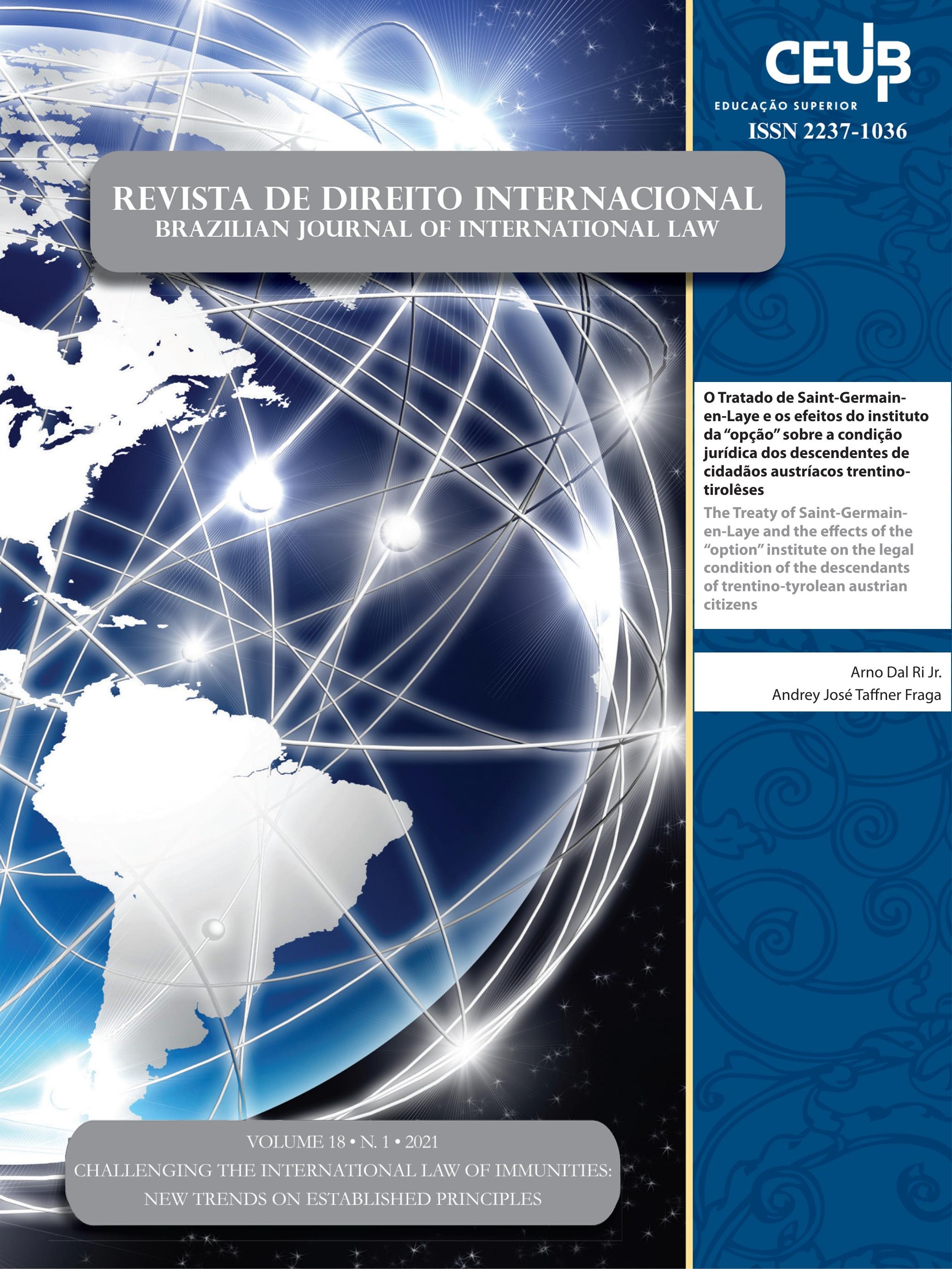


EDITORIAL

Challenging the International Law of Immunities: New Trends on Established Principles? An introduction to the special issue ............................................ 14

Lucas Carlos Lima, Loris Marotti e Paolo Palchetti

CrôniCAS........................................................................................ 17

RESPONSABILIDADE E IMUNIDADE DAS ORgANIZAÇÕES INTERNACIONAIS: PRÁTICA E DESAFIOS ...19 Vinícius Fox Drummond Cançado Trindade

The JURISDiCTIONAL IMMUNITY OF INTERNATIONAL ORgaNiZATIONS BEFORE THE BRAZILIAN SuPREMe Federal Court.

Bárbara Tuyama Sollero

The Law of State Immunity before the Brazilian Supreme Court: what is at stake WITH THE "ChANGRI-LA" CASE?

Aziz Tuffi Saliba e Lucas Carlos Lima

\section{Dossiê: Challenging the International Law of Immunities: New Trends} on Established Principles?

State Immunity and the Rights of Employees: Lights and Shadows of the Strasbourg COURT's JURISPRUdENCE .61

Pierfrancesco Rossi

A human Rights-BASEd CHALlENGE: THE KEY TO UNLOCK THE UN'S IMMUNiTY PROBLEM?...79 Héloïse Guichardaz

IMMUNITIES OF STATE OFFICIALS AND THE "FUNDAMENTALLY DIFFERENT NATURE" OF INTERNATIONAL COURTS: THE APPEALS CHAMBER DECISION IN THE JORDAN REFERRAL RE AL BASHIR ...97 Rita Guerreiro Teixeira e Hannes Verheyden 
IMUNIDADE DE JURISDIÇÃo dOS EsTADOS: O CAMINHO PARA A RELATIVIZAÇÃo

Vinícius Assis da Silveira, Luiz Felipe Costa Santana e Valesca Raizer Borges Moschen

The IMmUNity OF INTERNATIONAL ORganizations IN LABOUR DispUTES. DeVElopments BEFORE INTERNATIONAL TRIBUNALS, NATIONAL COURTS AND THE COLOMBIAN JURISDICTION ..... 137 Walter Arévalo-Ramirez e Ricardo Abello-Galvis

Imunidade de Jurisdição dos Estados E Poder Executivo brasileiro: os Pareceres dos CONSULTORES JURÍDICOS DO ITAMARATY

George Rodrigo Bandeira Galindo

Artigos SOBRe outros temas

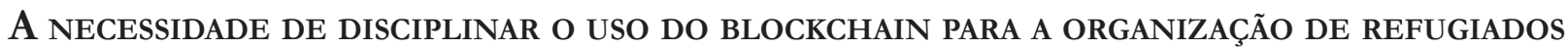
PELO DIREITO INTERNACIONAL. 195

Agatha Gonçalves Santana, Carla Noura Teixeira e Otavio Noura Teixeira

O TRABALHO INFANTIL DE MIGRANTES E REFUgIADOS VENEZUELANOS NO BRASIL

André Viana Custódio e ohana Cabral

THE NEW BRAZILIAN ANTI-TRAFFICKING LAW: CHALLENGES AND OPPORTUNITIES TO COVER THE NORMATIVE LACK . 243 Waldimeiry Correa da Silva

¿SON PARTE DEL BLOQUE DE CONSTITUCIONALIDAD LOS TRATADOS INTERNACIONALES DE DERECHOS HuMANOS DE LA OEA EN CHILE?: AVANCES EN BASE A LA DOCTRINA, NORMATIVA Y JURISPRUDÊNCIA. 270

Juan Pablo Díaz Fuenzalida

O Tratado de Saint-Germain-En-Laye e os Efeitos do instituto da “opÇão” Sobre a CONDIÇÃO JURÍDICA DOS DESCENDENTES DE CIDADÃOS AUSTRÍACOS TRENTINO-TIROLÊSES ......290 Arno Dal Ri Jr. e Andrey José Taffner Fraga

Control Judicial de la Corte Interamericana de Derechos Humanos y Programas Masivos de Reparaciones: Hacia un Enfoque más Matizado .309 Juan Carlos Ochoa-Sánchez 
JuSTICIABILIDADE DIRETA DOS DIREITOS ECONÔMICOS, SOCIAIS, CULTURAIS E AMBIENTAIS NA

Corte Interamericana DE Direitos Humanos..........................................................334

Augusto Antônio Fontanive Leal e Guilherme Massaú

How the indigenous case of Xukuru before the Inter-American Court of Human RiGHTS CAN INSPIRE DECOLONIAL COMPARATIVE STUDIES ON PROPERTY RIGHTS..........................353

Flavianne Fernanda Bitencourt Nóbrega e Camilla Montanha 


\title{
O Tratado de Saint-Germain-en-Laye e os efeitos do instituto da "opção" sobre a condição jurídica dos descendentes de cidadãos austríacos trentino-tirolêses*
}

\author{
The Treaty of Saint-Germain-en-Laye and the \\ effects of the "option" institute on the legal \\ condition of the descendants of trentino- \\ tyrolean austrian citizens
}

Arno Dal Ri Jr.**

Andrey José Taffner Fraga***

\section{Resumo}

O processo de nacionalização dos habitantes de territórios anexados pela Itália antes pertencentes ao Império austro-húngaro tem como premissa o instituto da "opção", que se encontra regulamentado nos artigos 70 a 82 do Tratado de Saint-Germain-en-Laye, um dos documentos que encerrou a Primeira Guerra Mundial. Neste, subsistia a necessidade de realização — no prazo de um ano - , de manifestação explícita em favor da manutenção da nacionalidade austríaca para os que residiam nos territórios anexados e possuíam a "pertinen₹̨a/ heimatrecht" nos termos do Tratado, e, na possibilidade de opção pela nacionalidade italiana, aos que haviam emigrado de tais territórios ainda como austríacos. O presente estudo, por meio dos métodos de análise empírica e de historiografia jurídica e de técnicas de pesquisa sobretudo bibliográficas, examinará aspectos da condição jurídica dos descendentes de emigrantes originários de tais territórios e que não realizaram a "opção", assim como as consequências jurídicas de sua ausência, em particular a isenção de responsabilidade internacional do Estado italiano e do nascente Estado republicano austríaco no que concerne a tais indivíduos. Conclui-se que os descendentes desses emigrados foram privados do reconhecimento de ambas as nacionalidades por meio do critério do ius sanguinis, permanecendo na condição jurídica de estrangeiros em relação a ambos os países até a emanação da Lei italiana n. ${ }^{\circ} 379$, de 2000. Este trabalho, assim, contribui para a compreensão de institutos de interesse (e pouco debatidos) para grande parcela da população brasileira, visto que a colonização trentino-tirolesa foi expressiva no país.

Palavras-chave: Tratado de Saint-Germain-en-Laye. Imigração trentinotirolesa. Cidadania italiana. Nacionalidade.

*** Mestrando em Teoria e História do Direito na Universidade Federal de Santa Catarina. Especialista (pós-graduado) em Direito Público Constitucional e Administrativo, pela UNIVALI, e em Direito Empresarial e Tributário, pelo INPG. Advogado.

E-mail: andreytaffner@gmail.com. 


\section{Abstract}

The nationalization process of the inhabitants of territories annexed by Italy previously belonging to the Austro-Hungarian Empire has as its premise the institute of "option", which is regulated in articles 70 to 82 of the Treaty of Saint-Germain-en-Laye, one of the documents that ended the First World War. Such document stated the need to carry out - within one year - an explicit demonstration in favor of maintaining Austrian nationality for those who resided in the annexed territories and who possessed "pertinenza/heimatrecht" under the terms of the Treaty, and the possibility of option, by Italian nationality, for those who had emigrated from such territories as yet Austrians. The present study, through the methods of empirical analysis and legal historiography and mainly bibliographic research techniques, will examine aspects of the legal status of descendants of emigrants from these territories who did not capitalize on the "option", as well as the legal consequences of this absence, in particular the exemption from international liability of the Italian State and the nascent Austrian Republican State regarding these individuals. It is concluded that the descendants of these emigrants were deprived of recognition of both nationalities based on the criterion of ius sanguinis, remaining in the legal status of foreigners to both countries until the enactment of Italian Law n. ${ }^{\circ} 379$, of 2000. The study thus contributes to the understanding of institutes of interest (and little discussed) for a large portion of the Brazilian population, since the trentino-tyrolean colonization was significant in the country.

Keywords: Treaty of Saint-Germain-en-Laye. Trentinotyrolean immigration. Italian citizenship. Nationality.

\section{Introdução}

Muito pouco lido, mas bastante citado na doutrina que, nas últimas três décadas, se formou tendo por objeto a condição jurídica dos cidadãos austríacos trentino-tiroleses que deixaram a terra natal antes de 1920 e de seus descendentes, o Tratado de Saint-Germain-en-Laye acabou por se revestir de uma conotação bastante negativa no universo jurídico que se dedica ao tema da nacionalidade devido às normas draconianas que continha ao prever o instituto da "opção". Por décadas, foi uma das normas que poderiam incidir nos processos de aquisição das nacionalidades austríaca e italiana, limitando o reconhecimento de ambas no caso dos imigrantes trentino-tiroleses que não haviam feito a "opção" nos termos do Tratado.

Assinado pela Áustria e pelas potências aliadas Estados Unidos, Reino Unido, França e Itália -, em 10 de setembro de 1919, o tratado colocou, juntamente àquele assinado em Versalhes, fim à Primeira Guerra Mundial, dividindo territórios do então já dissolvido Império Austro-Húngaro. Entre esses encontrava-se o Tirol, terra que nasce autônoma, como condado principesco, mas que, desde o ano de 1363, encontrava-se sob o domínio da Casa dos Habsburgo, sendo, portanto, parte da Áustria. Do ponto de vista geográfico, o Tirol se dividia em duas grandes áreas, a Setentrional, cuja capital era Innsbruck, e a Meridional, cuja capital era Trento'. Terra trilíngue, na primeira área habitavam - e ainda habitam - germanófonos, na segunda, habitavam os germanófonos de Bozen (Bolzano) e de Brixen (Bressanone), uma pequena minoria de língua reto-romanche (ladino) e, sobretudo, os italianófonos de Trento. É por esse motivo que os velhos emigrados, que partiram antes de 1920 de Trento e seus vales, diziam, orgulhosamente, ser do "Tirolo italiano", ou seja, austríacos por nascimento.

Passadas algumas décadas, já no final o século XX, os destinatários do dispositivo da "opção" previsto no Tratado de Saint Germain que tinham emigrado antes de 1920 e não optaram pela cidadania italiana no prazo fixado, assim como os seus descendentes, viram-se excluídos dos generosos termos da Lei italiana n. ${ }^{\circ}$ 91/1992, que regulamenta a aquisição da nacionalidade e reitera o "ius sanguinis" amplo como critério principal. Somente a posteriori, tornaram-se destinatários de uma normativa ad hoc, a Lei italiana n. ${ }^{\circ} 379 / 2000$, prevendo a abertura de novo prazo para realizar a "opção" por parte dos descendentes.

\footnotetext{
1 A porção de Trento (o “Tirolo italiano') manteve, de 1363 a 1806, uma relação feudal de vassalagem com os condes do Tirol, ao mesmo tempo que, institucionalmente e juridicamente, detinha uma soberania derivada do próprio Sacro Império Romano Germânico (CORSINI, Umberto. Problemi politico-amministrativi del Trentino nel nesso provinciale tirolese, 1815-1918. In: VALSECCHI, Franco; WANDRUSZKA, Adam (a cura di). Austria e province italiane 18151918: potere centrale e amministrazioni locali. Bologna: Il Mulino, 1977. p. 214). Com a queda do Sacro Império, após as turbulentas guerras napoleônicas, o Tirol italiano, no contexto da reorganização dos Estados europeus de 1814-1815 manteve-se com a Áustria, até sua anexação pela Itália.
} 
Nesse contexto, o presente artigo tem por objetivo analisar o impacto das normas do tratado de Saint Germain-en-Laye sobre a condição jurídica dos emigrantes trentino-tiroleses de nacionalidade austríaca e de seus descendentes, assim como a isenção de responsabilidade internacional do Estado italiano e do neonato Estado republicano austríaco em relação a tais indivíduos, derivada dos termos do referido tratado. Para tanto, se iniciará pela análise do contexto político que conduziu à assinatura do Tratado e a inserção nele do instituto da "opção", assim como as consequências jurídicas de tal instituto no que concerne aos emigrados trentinos-tiroleses que deixaram sua terra antes de 10 outubro de 1920, data de entrada em vigor do Tratado.

A hipótese a ser verificada é a de que referido Tratado, respeitado o prazo de um ano previsto na "opção" pela nacionalidade italiana, isenta de responsabilidade internacional o Estado italiano e o Estado austríaco no que concerne os cidadãos austríacos trentinos-tiroleses emigrados - e, consequentemente, seus descendentes - que deixaram de fazer a "opção", os quais figurariam na condição de estrangeiros frente as normas que regem a aquisição da nacionalidade nos ordenamentos jurídicos de ambos os Estados.

\section{Os bastidores do Tratado de Saint- Germain-en-Laye}

Ainda em plena guerra, em 26 de abril de 1915, os governos dos países que compunham a Tríplice Entente - Reino Unido, França e Rússia — assinaram com a Itália, na capital inglesa, o Tratado de Londres ${ }^{2}$, acordo que deveria ser mantido em segredo, mas que foi revelado ao mundo pela Rússia logo após a revolução bolchevique. Por meio desse instrumento, era sacramentada a entrada da Itália na guerra ao lado da Entente. Como

\footnotetext{
2 Também conhecido como "Pacto de Londres", o documento era composto por dezesseis artigos. Além do Tirol Meridional, a Itália receberia para a anexação a Veneza Júlia, com os planaltos cársicos e a península istriana, um terço da Dalmácia, com as cidades de Zara e Sebenica, parte da Albânia e a bacia carbonífera de Adália, na Turquia, assim como a confirmação da soberania sobre a Líbia e sobre as ilhas de Dodecaneso, na Grécia. No caso de repartição das colônias alemãs na África, a Itália ainda receberia compensações territoriais aumentando as suas próprias colônias na Líbia, Eritreia e Somália. Disponível em: RENZI, William A. In the shadow of the sword: Italy's neutrality and entrance into the Great War, 1914-1915. New York: Peter Lang, 1987.
}

recompensa ao Estado italiano, o tratado trazia o compromisso de, ao final da guerra e em caso de vitória, legitimar a anexação de territórios até então pertencentes ao Império Austro-húngaro há muito ambicionados pelo governo de Roma. Nesse sentido, a cláusula quarta do referido Tratado previa que:

sob o tratado de paz a Itália obterá o Trentino, o Tirol cisalpino com a sua fronteira geográfica e natural, o Brennero, a cidade de Trieste e os seus arredores, o condado de Gorizia e Gradisca, toda a Ístria até Quarnero, compreendida nessa Volosca, e as ilhas istrianas de Cherso e Lussino, assim como as pequenas ilhas de Plauno, Unie, Canidole, Palazzuoli, São Pedro dos Nembi, Asinello e Gruica com as ilhotas dos seus arredores. ${ }^{3}$

Em novembro de 1919, com o fim da Guerra e a vitória da Tríplice Entente, as tropas italianas ocuparam todo o território do Tirol, tomando Innsbruck e alcançando Kufstein, ponto final de fronteira com a Alemanha. A intenção era, sem dúvida, forçar a renegociação dos termos do Tratado de Londres e anexar todo o antigo condado. Nos palácios do governo italiano, Ettore Tolomei ${ }^{4}$, inclusive, sugeria, oficialmente, denominar a "nova província" a ser anexada de "Enaponte", uma grosseira italianização do nome da capital tirolesa.

Nas negociações que levaram ao texto final do Tratado de Saint-Germain-en-Laye, britânicos e franceses colocaram limites às pretensões italianas. Vittorio Emanuele Orlando, primeiro-ministro italiano e chefe da delegação na conferência de Saint-Germain-en-Layé, sofreu um grande revés, com o comando aliado man-

3 TRATADO de Londres = Treaty of London. Reino Unido, 26 abr. 1915. In: GREAT BRITAIN. Parliamentary Papers. London: LI Cmd. 671, Miscellaneous, n. 7, p. 2-7, 1920.

${ }^{4}$ Disponível em: FERRANDI, Maurizio. Ettore Tolomei: l'uomo che inventò l'Alto Adige. Trento: Publilux, 1986. No que concerne especificamente aos mecanismos de repressão institucionalizados pelo regime fascista no Tirol Meridional: REUT-NICOLUSSI, Eduard. Tyrol under the axe of Italian fascism. London: Allen \& Unwin Limited, 1930.

5 A Teoria de Tolomei, apresentada sem nenhuma base histórica, afirmava que a população autóctone era herdeira de uma legião romana que teria desaparecido entre as montanhas do Tirol Meridional e teria batizado Innsbruck de Enaponte. Conforme dizia o próprio Tolomei, sua iniciativa buscava "restituire [...] nell'uso le voci originarie latine od italiane, quasi irriconoscibili in molti casi sotto la secolare deformazione tedesca, e talora sostituire alcuni nomi, ed anche crearne [...] apparecchiare una completa nomenclatura italiana [...] [ed imprimere] fino all'ultimo casolare, il sigillo perenne del nazionale dominio". In: KRAMER, Johannes. La toponomastica altoatesina nel contesto europeo. Archivio per l'Alto Adige, 2003. v. 4. p. 282. Ainda a respeito das tentativas de Tolomei de italianizar o Tirol: GRUBER, Alfons. Storia del sudtirolo: eventi cruciali del XX secolo. Bolzano: Athesia, 2010. p. 33 ss. 
dando as tropas italianas se retirarem do Tirol Setentrional. E, com isso, foi apresentada a proposta, temida pelos italianos, mas também pelos tiroleses, de unir todos os povos alemães da Áustria em um único Estado com a Alemanha ${ }^{6}$. Em outros termos, seguiam o que dizia o presidente americano, Woodrow Wilson: as futuras fronteiras italianas deveriam ser traçadas "ao longo de linhas claramente reconhecíveis de nacionalidade".

Inconformada, a Itália, porém, não se deu por vencida. Sem a possibilidade de anexar "Enaponte" e, com isso, todo o Tirol, concentrou-se em anexar Bozen e Trento, conforme previsto originalmente no Tratado de Londres, de 1915. A autorização para anexar Trento era dada por certa. Sem compreender a complexidade da história local e tentando a todo custo desmontar a estrutura territorial do ex Império Austro-húngaro, os vencedores utilizaram, no caso de Trento, a língua comum italiana para legitimar a anexação. Com Bozen e Brixen, por sua vez, a situação era bem mais complexa. Por mais que o Tratado de Londres tivesse previsto, explicitamente, a anexação do Tirol Meridional, os fatores linguístico e cultural eram um obstáculo significativo à medida que o mencionado presidente Wilson tinha determinado que as fronteiras da Itália deveriam seguir critérios de nacionalidade.

Vittorio Emanuele Orlando e sua delegação, contradizendo todos os pressupostos teóricos que Pasquale Stanislao Mancini ${ }^{8}$ elaborou para justificar a criação

\footnotetext{
${ }^{6}$ A proposta foi amplamente debatida no período, tendo como principal artífice o ministro dos negócios exteriores austríaco, Otto Bauer, parte do governo provisório de matriz socialdemocrata que tomou posse em Viena logo após o final da guerra. Teve como efeito direto o fato de os vencedores, para evitar a concretização dessa hipótese, inserirem no artigo 88 do tratado a proibição explícita da união entre a nascente República da Áustria com qualquer outro Estado: "the independence of Austria is inalienable otherwise than with the consent of the Council of the League of Nations. Consequently Austria undertakes in the absence of the consent of the said Council to abstain from any act which might directly or indirectly or by any means whatever compromise her independence, particularly, and until her admission to membership of the League of Nations, by participation in the affairs of another Power". Disponivel em: HAAS, Hanns. Österreich und die Alliierten 1918-1919. In: ACKERL, Isabella (hrsg.). Saint-Germain 1919: Protokoll des Symposiums am 29. und 30. Mai 1979 in Wien. Wien: Geschichte und Politik, 1989.; e, HANISCH, Ernst. Der große Illusionist: Otto Bauer (1881-1938). Wien: Böhlau, 2011.

KNIPPENBERG, Hans; MARKUSSE, Jan. Nationalising and Denationalising European Border Regions, 1800-2000: views from Geography and History. Berlin: Springer Science, 2012. p. 134.

8 Político, jurista e professor nas Régias Universidades de Nápoles, de Roma e de Turim, Pasquale Stanislao Mancini nasceu em Castel Baronia, em 1817, e morreu em Nápoles, em 1888. Foi Ministro
}

do Estado italiano?, assim como aqueles que eram usados à favor da anexação de Trento e de Trieste (o "irredentismo") ${ }^{10}$, ou seja, de que as Nações deveriam ser

da Instrução Pública (1862), da Justiça (1876) e dos Negócios Exteriores (1881) do Reino da Itália. Publica, em 1873, o livro "Diritto internazionale", no qual apresenta a sua teoria sobre a nacionalidade. Sobre Mancini: DAL RI JR., Arno. A nação contra o Estado: a ciência do direito internacional no "Risorgimento" italiano. Anuário Brasileiro de Direito Internacional, v. 6, p. 6, 2011. p. 69 ss.; STORTI, Claudia. Pasquale Stanislao Mancini. In: BIROCHI, Italo; CORTESE, Ennio; MATTONE, Antonello; MILETTI, Marco Nicola (a cura di). Dižionario Biografico dei Giuristi Italiani: XII - XX secolo. Bologna: Il Mulino, 2013. v. 2. p. 1244 ss.; VIDARI, Gian Savino Pene. La prolusione di Pasquale Stanislao Mancini sul principio di nazionalità (1851). In: CAZZETTA, Giovanni (a cura di). Retoriche dei giuristi e costruzione dell'identità nazionale. Bologna: Il Mulino, 2013. 117 ss.; e, a introdução escrita por Tito Ballarino à obra MANCINI, Pasquale S. Direito internacional. Ijuí: Unijuí, 2003.

9 Baluarte da teoria elaborada por Mancini, o Princípio das Nacionalidades tinha por base uma concepção bastante romantizada de "Nação", típica do século XIX, que dizia que somente eram italianos aqueles de língua, cultura e tradições típicas, ligados também por vínculos étnicos, pela "razza". Somente poderia ser membro da "Nação" italiana, portanto, o filho de um italiano. Os elementos dessa concepção receberam um primeiro delineamento em um universo eminentemente político, em que correntes de matriz nacionalista tentavam legitimar a independência de determinados territórios europeus - como a Itália, a Polônia ou a Hungria submetidos de modo integral ou fragmentário à soberania de Estados terceiros. Tal fenômeno pode ser facilmente observado ao longo da primeira metade do século XIX, sobretudo na cultura jurídicopolítica italiana e francesa. Entre os italianos que aderiram a esse movimento, se destacam juristas importantes do período, tais como Pellegrino Rossi, Gian Domenico Romagnosi, Giuseppe Mazzini, Luigi Taparelli D’Azeglio, Giacomo Durando e Vincenzo Pagano. Elementos que vão compor os conceitos de "Nações" e "Nacionalidade" e que influenciar o Risorgimento podem ser encontrados em ROMAGNOSI, Gian Domenico. La scienza delle costituzioni. Firenze: A Spese Degli Editori, 1850.; MAZZINI, Giuseppe. Nazionalità: qualche idea su una costituzione nazionale. In: Edizione nazionale degli scritti di Giuseppe Mazzini. Imola: Galeati, 1908. v. 6.; D’AZEGLIO, Luigi Taparelli. Della nažionalità. Genova: Ponthenier, 1847.; DURANDO, Giacomo. Della nažionalità italiana: saggio politico-militare. Losanna: Bonamici, 1846.; PAGANO, Vincenzo. Del diritto della nazionalità italiana. Napoli: Rondinella, 1861. A respeito, DAL RI JR., Arno. A nação contra o Estado: a ciência do direito internacional no "Risorgimento" italiano. Anuário Brasileiro de Direito Internacional, v. 6, p. 6, 2011. p. 69 ss. Sobre o impacto dessa doutrina na América do Sul: DAL RI JR., Arno. Mancini in the Platine Basin: the reception of the Principle of Nationalities in Argentina, Uruguay and Brazil. Forum Historiae Iuris. Internetzeitschrift für Rechtsgeschichte in Europa. 2018. Disponível em: https:// forhistiur.de/en/2018-12-dal-rijr/abstract/?l=en. Acesso em: 06 nov. 2020.

${ }_{10}$ Trata-se de movimento que reivindicava o caráter nacional italiano das porções territoriais que, apesar de povoadas por populações de língua e cultura italianas, não pertenciam ao Reino da Itália. Em meados do século XIX, tal movimento tomou proporções maiores na porção sul do Tirol (atual Trentino), apesar de a população estar claramente dividida: grande parte das elites intelectuais urbanas defendia o nacionalismo italiano, ao passo que a grande massa da população camponesa permanecia fiel à casa real dos Habsburg, es- 
agregações de indivíduos com uma mesma língua, cultura e raça, utilizaram um questionável critério geográfico para anexar, além do "Tirolo italiano", também a parte do Tirol Meridional que falava alemão e reto-romanche, sem nenhum vínculo histórico e cultural com a Itália. Além disso, as pretensões italianas também colidiam com os critérios do Presidente Wilson. O lema da delegação italiana na espera de finalmente obter o botim nos Alpes, diversas vezes afirmado por Orlando, era, por sua vez, que a fronteira da Itália deveria "coincidir com a fronteira natural que Deus lhe deu"11. Como a passagem do Brennero era o ponto mais alto dos Alpes entre Itália e Áustria sendo, portanto, fronteira natural, tudo o que estivesse ao sul era projeção da península e deveria ser italiano.

Orlando ilustra essa pretensão em um discurso proferido em março de 1919, enquanto primeiro-ministro, na Câmara dos Deputados do reino italiano, em que afirma que a Itália:

[...] não pede a mais, mas não poderia admitir menos do que isso: reunir consigo terras e gentes de gloriosa tradição italiana, e se fechar, para a sua integridade e para a sua defesa, dentro das fronteiras que a própria natureza lhe deu, tornando-se ao mesmo tempo o País mais claramente configurado e o povo etnicamente mais coeso entre os países e povos que a Europa compreende. ${ }^{12}$

Da questão geográfica advinha uma segunda, muito mais significativa. Tomar por inteiro o território do Tirol Meridional até a passagem do Brennero era assumir o controle da principal porta de entrada que as tropas alemãs eventualmente poderiam tentar utilizar em uma futura invasão. A preocupação com a instabilidade política europeia do pós-guerra e com a possibilidade de um novo conflito armado evidenciava a complexidade

pecialmente após a breve experiência de anexação ao Reino da Itália durante as invasões napoleônicas, na qual se experimentou aumento de impostos, convocações para guerra e uma base política mais liberal, maçônica e anticlerical (SCHOBER, Richard. Il Trentino durante il periodo di unione al Tirolo: 1815-1918. In: VALSECCHI, Franco; WANDRUSZKA, Adam (org.). Austria e province italiane 1815-1918: potere centrale e amministrazioni locali. Bologna: Il Mulino, 1977. p. 185). O irredentismo se manifestou também (e principalmente) por meio das "sociedades patrióticas" — Società Pro Patria, Lega Nazionale, Dante Alighieri — que buscavam difundir a língua e cultura italianas na região (ZIEGER, Antonio. Storia della Regione Trentina. 2. ed. Trento: Dolomia, 1981. p. 378-379).

11 "coincidere con la frontiera naturale che Dio le ha dato".

12 Intervento del Presidente del Consiglio dei ministri, Vittorio Emanuele Orlando, seduta del $1^{\circ}$ marzo 1919. In: ITALIA. Atti Parlamentari. Camera dei Deputati. XXIV Legislatura. 1. sessione. Roma: Camera dei Deputati, 1919. p. 18077. dessa questão, que era explorada inclusive pela imprensa italiana:

o valor estratégico do Alto Ádige sempre foi reconhecido. No vale superior do Ádige se encontra o nó de todas as estradas para a invasão alemã na Itália. Quando a Itália tem Trento, os alemães ainda teriam lá em cima a porta da Itália nas próprias mãos. É necessário que a Itália, além de Bolzano, chegue também à Bressannone para que os alemães, com o cruzamento das duas ferrovias que passam nos Alpes, em Brennero e em Dobbiaco, não se tornem todavia patrões do lado italiano. Um general austríaco, Kuhn, deixou escrito: "Os italianos devem conquistar o Tirol Meridional até o Brennero se querem defender Veneza". ${ }^{13}$

Com a assinatura do Tratado de Saint Germain-en-Layé, foi sacramentada a anexação do Tirol Meridional para a Itália, o que representou um incremento de 250.000 habitantes em termos populacionais, a conquista de posições territoriais estratégicas na fronteira norte e de um importante potencial hidrelétrico ${ }^{14}$. O fim da Primeira Guerra e a assinatura do Tratado de Saint Germain-en-Laye também significaram o esfacelamento de seu antigo inimigo, o Império Austro-húngaro ${ }^{15}$.

13 LE REIVINDICAZIONI italiane illustrate alla Conferenza di Parigi: il memoriale dell'On. Barzilai. Il Messaggero, Roma, 12 mar. 1919.

14 FENET, Alain. La question du Tyrol du Sud: un problème de droit international. Paris: Librairie Générale de Droit et de Jurisprudence, 1968. p. 32.

15 Esfacelamento que pode ser resumido na famosa (apesar de nunca confirmada) frase que teria sido dita quando da convenção do Tratado de Saint Germain por Georges Clemenceau, primeiro ministro francês, ao se referir à definição territorial da nova República da Áustria pós-Tratado: "Ce qui reste, l'est l'Autriche" - "Isso que sobrou, é a Áustria” (SCHÜSSEL, Wolfgang. Federalism in a changing world, learning from each other: scientific background, proceedings, and plenaries of the International Conference on Federalism 2002. In: BLINDENBACHER, Raoul; KOLLER, Arnold (org.). International Conference on Federalism. University of St. Gallen, 2002. Montreal: McGill-Queen's University Press, 2003. p. 567-570. p. 567). O desmantelamento do Império colocava fim a uma rivalidade entre Itália e Áustria que remontava às discussões sobre fronteiras do período final das guerras napoleônicas, quando, em 1809, mesmo ano da famosa revolta tirolesa comandada por Andreas Hofer contra o domínio bávaro sobre o Tirol (ZIEGER, Antonio. Storia della Regione Trentina. 2. ed. Trento: Dolomia, 1981. p. 302-303), a porção meridional do território tirolês foi consignada ao Reino da Itália, por ocasião do acordo de paz de Schönbrunn. O império austríaco, porém, reverteu essa situação e, já nos anos de 1814-1815, durante o Congresso de Viena, reintegrou todo o Tirol ao seu território, além de estender seu domínio às regiões do Vêneto e da Lombardia (BOLLER, Daiana. Welschtirol: il territorio trentino nell'impero asburgico. Bolzano: Athesia, 2014. p. 22). A Itália nunca se conformou com essa situação e, mesmo depois de englobar o Vêneto e a Lombardia em seus domínios, continuou almejando outras anexações. Conforme Alain Fenet (FENET, Alain. La question du Tyrol 
Nos territórios anexados, a consternação ${ }^{16}$ e mesmo o estado de negação eram grandes ${ }^{17}$. Abria-se um capítulo de conflitos e desentendimentos que, malgrado o passar dos anos, não encontrou plena solução.

du Sud: un problème de droit international. Paris: Librairie Générale de Droit et de Jurisprudence, 1968. p. 32), o Tratado de Saint Germain e a dissolução do império austro-húngaro representaram, para a Itália, a derrota de um inimigo secular.

16 A capa da edição do jornal "Bozner Nachrichten", publicada em 12 de outubro de 1920, dois dias após a entrada em vigor do tratado e da consequente anexação, reporta a reação da população na capital do Tirol, Innsbruck: "Der gestrige sonnige Oktobertag war der Tag der Traner und des Abschiedes. Die schwarzen Fabnen in den Straßen der Stadt bannten den Blick und ließen ibn nicht hinausgehen ins tiefe Blau des Herbsthimmels. Den ganzen Tag über blieben die Glocken der Kirchen unserer Stadt still. Kein Mittagsläuten vernahm man und man dachte an das deutsche Land im Süden, in dem an diesem Tage ebenfalls alle Glocken schwiegen, zum Zeichen der Trauer um die ins Grab gesunkene Vergangenheit. Um 9 Ubr fand in der Pfarrkirche St. Jakob ein Trauergottesdienst statt, dem im Landhause eine gemeinsame Sitzung des Landesrates und der Landesregierung folgte. Der Gemeinderat und die Handels- und Gewerbekammer bielten ebenfalls Trauersitzungen ab". Logo após, na segunda página do mesmo jornal, vinha narrada a situação na cidade de Bolzano, agora parte do território italiano: "Der gestrige Sonntag verlief in Bozen ernst und rubig. Es wurde keinerlei Vergnügungen abgehalten und nachmittags erweckte die fast menschenleeren Straßen den Eindruck, als ob sie Stadt ausgestorben wäre".

17 São emblemáticas desse contexto as atitudes do então prefeito de Bolzano, Julius Perathoner, que se recusou a remover os símbolos da dinastia dos Habsburg dos edifícios públicos, a saudar o rei da Itália em idioma italiano durante a visita de 1921 (GROTE, Georg. The South Tyrol question, 1866-2010: from national rage to regional state. Bern: Peter Lang International Academic Publishers, 2012. p. 31) e, como narrado por Thomas Sinha (SINHA, Thomas. Il sindaco di Bolzano scrive al sindaco di Trento: Historegio. Ufficio comune dell'EUREGIO Tirolo - Alto Adige - Trentino. Disponível em: https://historegio.europaregion.info/it/settimana-attuale-100-annifa.asp?news_action $=4 \&$ news_article_id $=644028 \#$ accept-cookies. Acesso em: 15 out. 2020.), remeteu carta ao prefeito de Trento, em resposta ao convite para participar das festividades alusivas à anexação, na qual dizia: "è un vecchio proverbio tedesco: Chi ha il danno non ha bisogno di occuparsi delle beffe. E non è altro che una beffa da parte della Signoria Vostra l'invitarmi ad una festa destinata a celebrare la pace di sopraffazione di S. Germano in forza della quale la città di Bolzano, insieme col resto del 'Südtirol' tedesco - ad onta di tutte le proteste contro la violazione del diritto di autodeterminazione messo dal presidente a base della pace, violazione che grida vendetta al cielo - venne separata e incorporata in uno stato di lingua straniera". A Itália, por sua vez, passou a exercer soberania sobre uma população e cultura que lhe eram absolutamente estranhas. Não foram poucos os episódios de graves desentendimentos e choques. Georg Grote (GROTE, Georg. The South Tyrol question, 1866-2010: from national rage to regional state. Bern: Peter Lang International Academic Publishers, 2012. p. 33) narra, por exemplo, os acontecimentos envolvendo as celebrações da noite de São João, comemoradas com fogueiras e disparos de armas de fogo no Tirol do Sul. Tal episódio, resultou na prisão de vários participantes sob a acusação de "atos violentos". Os envolvidos foram levados acorrentados para Trento onde foram julgados e condenados.

\section{0 instituto da "opção" no Tratado de Saint-Germain-en-Laye}

O modo como foi implementada a anexação dos territórios até então pertencentes ao Império Austro-Húngaro pelo Estado italiano foi incomum para a própria Itália. Ao longo de quase uma década durante a segunda metade do século XIX, a unificação foi realizada incorporando os pequenos e centenários Estados então existentes à península por meio de plebiscitos em que a população masculina residente sobretudo nas cidades era consultada ${ }^{18}$. Aparentemente democrático e mais adequado a um mundo de "nações civilizadas", o instituto do plebiscito foi o principal instrumento de legitimação da unificação italiana, sendo já considerado na práxis, e também pela doutrina, como consolidado devido, também, ao seu uso em outros casos envolvendo a França e a Áustria ${ }^{19}$.

O processo que culminou na anexação dos territórios que pertenciam ao Império Austro-Húngaro seguiu uma outra linha em relação àquela adotada na unificação italiana devido, sobretudo, à forte presença de minorias linguísticas diferentes das neolatinas que compõem o tronco itálico - comuns entre todos os territórios que passaram a fazer parte da Itália com a unificação, entre 1861 e 1866. Essa heterogeneidade linguística e cultural reforçou a ideia de que a "opção" seria o instituto apropriado ao contexto, em detrimento do "plebiscito". Em outros termos, a presença de realidades étnicas, linguísticas e culturais, muito diferentes da italiana, passaria a exigir um confirmação individual de cada cidadão residente nos territórios anexados acerca da adesão ao ordenamento jurídico e à realidade cultural aos quais pretendia pertencer, entre antigo e novo, tendo como consequência imediata a definição da sua própria nacionalidade.

A consequência concreta de tal contexto impunha ao indivíduo residente nesses territórios a nacionalização como italiano não apenas do ponto de vista jurídico,

18 CAPUZZO, Ester. Dalla pertinenza austriaca alla cittadinanza italiana. Atti della Accademia Roveretana degli Agiati di Scienze Lettere ed Arti, Rovereto, Italia, s. 8, v. 10, n. 2, atti A, 2010. Disponível em: https://agiati.org/atti-a-2010-ii. Acesso em: 05 set. 2020. p. 66.

19 É o caso, entre outros, dos tratados assinados entre Prússia e Áustria, em 28 de outubro de 1866; entre a França e a Suécia, em 25 de março de 1878; entre Perú e Chile, em 20 de outubro de 1883. Sobre uso dos plebiscitos no direito internacional do século XIX: STOERK, Félix. Option und Plebiscit bei Eroberungen tend Gebietscessionen. Leipzig: Duncker und Humblot, 1879. 
mas também cultural e linguístico, se quisesse ali permanecer. Como relata Paolo Cova, nesse sentido, "qualquer pessoa que não falasse a língua do Estado-nação no qual ele estava após o acordo de paz poderia, se quisesse, mudar-se para o estado de sua própria raça, onde a mesma língua era falada" ${ }^{20}$. A previsão do instituto da "opção" demonstra, portanto, como no âmbito do tratado "[...] o princípio da supremacia do estado-nacional monoétnico ainda determina claramente os direitos das pessoas de residir em seu local de nascimento" ${ }^{21}$.

\subsection{Delineamentos da "opção" precedentes ao Tratado de Saint-Germain-en-Laye}

O processo de integração disposto com a firma do Tratado de Saint-Germain-en-Laye, em 10 de setembro de 1919, não previa o plebiscito como procedimento de assimilação. Os aliados, ao contrário, abençoaram a anexação pela Itália dos territórios do Tirol Meridional, constituído por populações de língua alemã, reto-romanche e italiana, sem dispor sobre a necessidade de realização de uma consulta ou plebiscito ${ }^{22}$. Para amenizar o problema, no campo diplomático, tentaram-se

\footnotetext{
${ }^{20}$ COVA, Paolo. Der große Betrug: das optiondrama der deustchsrachigen Inseln im Trentino. Palai en Bersntol: Istituto Culturale Mocheno, 2014. p. 31.

${ }^{21}$ COVA, Paolo. Der große Betrug: das optiondrama der deustchsrachigen Inseln im Trentino. Palai en Bersntol: Istituto Culturale Mocheno, 2014. p. 31.

22 As razões para tal atitude poderiam ser assim resumidas: 1) as novas fronteiras do Estado italiano não estavam obedecendo os critérios de nacionalidade fixados nos famosos 14 pontos do programa de paz do presidente estadunidense Woodrow Wilson, tendo em vista que, como mencionado, a Itália englobou territórios de população de língua alemã, reto-romanche, eslava e croata; 2) o temor das consequências que a inclusão das minorias étnico-linguísticas poderiam representar à unidade do Estado italiano; e, 3) a suposta necessidade de se estabelecer a dita "fronteira natural" do norte da Itália nos alpes, por razões de defesa militar (CAPUZZO, Ester. Dalla pertinenza austriaca alla cittadinanza italiana. Atti della Accademia Roveretana degli Agiati di Scienze Lettere ed Arti, Rovereto, Italia, s. 8, v. 10, n. 2, atti A, 2010. Disponível em: https://agiati.org/atti-a-2010-ii. Acesso em: 05 set. 2020. p. 66-67). Além dessas razões, poderiam, também, ser citados os argumentos que Henri Bonfils esgrimava no âmbito doutrinário: "le principe $d u$ plébiciste, une fois adopté, entrainerait à de graves et dangereuses conséquences. Admettez-vous la necessite du suffrage populaire dans le cas d'une cession spontanée ou imposée d'une province à une outre État, vous ne pouvez. repousser la prétention qu'élèverait une partie d'un État à se séparer absolutement des autres parties à se donner à un autre État, on à se constituer en État indépendant. Comment contraindre à l'Union nationale telle fraction dont la volonté a changé, dès que ce changement de volonté peut être constaté par le suffrage des citoyens? Si le plébiscite a seul le pouvoir efficace de dissoudre les liens politiques, il doit être aussi seul suffisant pour cette oenvre". BONFILS, Henri. Manuel de droit international public. Paris: A. Rousseau, 1905. p. 325.
}

estabelecer critérios para que a população pudesse ao menos optar pela nacionalidade italiana ou austríaca. Tais critérios forma inseridos, justamente, nos artigos 70 a 82 da Seção VI (Cláusulas relativas à cidadania) do tratado.

O instituto da "opção" não representava na época uma novidade no campo do direito internacional. Teve, de fato, uso em diversos contextos do século XIX, uma vez que era concebido e aplicado, principalmente, em situações envolvendo populações de territórios anexados. Na doutrina, a "opção" é descrita por Theóphile Funck-Brentano e Albert Sorel como um instituto jurídico em que "o Estado cedente cumpria um dever para com os seus antigos súditos, o Estado cessionário cumpria um dever em relação aos seus novos súditos, estipulando no tratado para os habitantes do território cedido, o direito de optar entre a nacionalidade que possuíam antes do tratado e aquela que o tratado lhes atribui ${ }^{23}$ ". Para os autores, na época, as condições em que esse direito poderia ser exercido "[...] são mais ou menos liberais, conforme o Estado cessionário está mais ou menos convencido da facilidade com a qual se realizará a assimilação dos habitantes do território cedido com os habitantes da sua nova pátria $[. . .]^{24 \prime}$. Logo a seguir são listados alguns requisitos que os tratados de cessão do território devem observar quando regulamentam a “opção". Em outros termos, o tratado determina ${ }^{25}$ :

[...] as condições nas quais a opção pode ser feita; fixa o tempo em que o direito de opção pode ser feito; regulamenta a situação das pessoas originárias do território cedido que nesse não se encontram na época da cessão; regulamenta igualmente os direitos dos menores; estipula em geral franquias aduaneiras para os móveis e os efeitos para os habitantes que querem mudar seu domicílio para fora do território, e para aquelas pessoas originárias do território que o deixaram e que desejam a ele retornar.

A aplicação clássica desse instituto estava prevista, por exemplo, no Tratado de Turim, por meio do qual se dava a anexação da Savoia e do condado de Nice pela França, assinado em 24 de março de 1860, cujo artigo 6 dispunha:

os súditos sardos, originários da Savoia e dos arredores de Nice, ou domiciliados atualmente

\footnotetext{
${ }^{23}$ FUNCK-BRENTANO, Théophile; SOREL, Albert. Précis du droit des gens. Paris: E. Plon, 1877. p. 503.

${ }^{24}$ FUNCK-BRENTANO, Théophile; SOREL, Albert. Précis $d u$ droit des gens. Paris: E. Plon, 1877. p. 503.

25 FUNCK-BRENTANO, Théophile; SOREL, Albert. Précis du droit des gens. Paris: E. Plon, 1877. p. 503.
} 
nessas províncias, que entenderem conservar a nacionalidade sarda, gozarão, durante o espaço de um ano à partir da troca das ratificações e, por meio de uma declaração prévia feita à autoridade competente, da faculdade de mover seu domicílio para a Itália, e de ali se fixar, caso no qual será mantida a qualidade de cidadão $\operatorname{sardo}^{26}$.

Com o passar dos anos, a doutrina não somente analisava questões de ordem técnica, mas também passou a legitimar a utilização da "opção" nos tratados de anexação, salientando a necessidade de respeitar questões éticas que até pouco preocupavam os Estados. Nesse sentido, o jurista belga Ernest Nys, em 1892, afirmava

os habitantes do território cedido devem consentir a alienação? Se o consentimento deles não é necessário, devem ter o direito de opção, ou seja, a escolha entre a conservação da sua nacionalidade original e a aquisição da nacionalidade nova? Um sábio historiador do direito afirma que no século XIV e no começo do século XV, existia uma regra geralmente admitida que nenhuma anexação poderia ser pronunciada sem o consentimento do povo e dos notáveis ${ }^{27}$.

Essa mesma preocupação de cunho ético levou Carlo Bisocchi a identificar uma alteração na perspectiva com que o instituto tinha sido aplicado no que concerne, em particular, aos efeitos secundários que poderia ter sobre os indivíduos por ela atingidos e seus respetivos patrimônios, afirmando que, se de um lado, tinha se tornado uma "[...] prática constante dos Estados realizar após cada modificação territorial uma modificação correspondente também na nacionalidade da população dos territórios anexados ${ }^{28}$ ", por outro, o fenômeno colidia com os "princípios solenemente proclamados nesses últimos tempos por quase todos os povos civilizados, em matéria de direitos individuais ${ }^{291}$ ", situação que acabava por salientar "[...] uma certa contradição de tal sistema com tais direitos ${ }^{30 "}$. Essa contradição, por sua vez, fez com que emergisse a compreensão de que "se é justo que toda anexação produza ipso facto uma mutação de soberania, não é, porém, justo que esta circunstância produza ipso facto também uma mutação de nacionali-

\footnotetext{
${ }^{26}$ Sobre o assunto: WEISS, André. Manuel de droit international privé. Paris: Sirey, 1914. p. 174 ss., e BONFILS, Henri. Manuel de droit international public. Paris: A. Rousseau, 1905. p. 232 ss.

${ }^{27}$ NYS, Ernest. Le droit international: les principes, les théories, les faits. Bruxelles: Moens, 1912. t. 2. p. 18.

28 BISOCCHI, Carlo. Acquisto e perdita della nazionalità nella legislazione comparata e nel diritto internazionale. Milano: Hoepli, 1907. p. 346.

29 BISOCCHI, Carlo. Acquisto e perdita della naz̧ionalità nella legislaz̨ione comparata e nel diritto internazionale. Milano: Hoepli, 1907. p. 346.

30 BISOCCHI, Carlo. Acquisto e perdita della nazionalità nella legislazione comparata e nel diritto internazionale. Milano: Hoepli, 1907. p. 346.
}

dade na população ${ }^{31}$ ". O posicionamento de Bisocchi quanto ao tema era muito claro, ou seja, os direitos individuais dos habitantes das áreas anexadas deveriam ser respeitados, fazendo com que as necessidades dos Estados devessem "ser conciliadas com os direitos dos indivíduos ${ }^{32}$ ", uma vez que a conservação ou mudança de cidadania "é reconhecida quase em todos os lugares, em via geral, como um direito pessoal, assim é lógico que no próprio caso de uma naturalização coletiva o elemento da vontade tenha deva ocupar aquele lugar que lhe diz respeito em toda esta matéria ${ }^{33}$ ".

Do ponto de vista prático, o artigo segundo do Tratado de Frankfurt, firmado em 10 de maio de 1871 e que encerrava a guerra franco-alemã com a anexação da Alsácia e da Lorena pela Alemanha, comprovava a tese de Bisocchi, por ter apresentado no seu texto parte dessas preocupações:

os súditos franceses, originários dos territórios cedidos, domiciliados atualmente nesse território, que entenderem conservar a nacionalidade francesa, gozarão até 1 . de outubro de 1872, e por meio de uma declaração prévia feita à autoridade competente, da faculdade de mudar seu domicílio na França e de ali se fixar, sem que esse direito possa ser alterado pelas leis sobre o serviço militar, caso no qual será mantida a qualidade de cidadão francês ${ }^{34}$.

A segunda parte desse mesmo dispositivo, porém, seguindo o que posteriormente iria aludir Carlo Bisocchi, acrescenta duas novas perspectivas acessórias bastante significativas para a "opção", ou seja, prevê, explicitamente, que ela não gerará efeitos sobre o patrimônio em território anexado do cidadão que optou por conti-

\footnotetext{
31 BISOCCHI, Carlo. Acquisto e perdita della naz̧ionalità nella legislaz̨ione comparata e nel diritto internazionale. Milano: Hoepli, 1907. p. 346.

32 BISOCCHI, Carlo. Acquisto e perdita della naz̧ionalità nella legislazione comparata e nel diritto internazionale. Milano: Hoepli, 1907. p. 346.

33 BISOCCHI, Carlo. Acquisto e perdita della naz̧ionalità nella legislaz̨ione comparata e nel diritto internazionale. Milano: Hoepli, 1907. p. 346.

34 Em 30 de março de 1872, Jules Dufaure, ministro da justiça da França, publicou uma circular confirmando a interpretação do tratado e indicando que "[...] tous ceux qui sont nés dans les territoires cédés, quels que soient leur âge, leur sexe et leur domicile, sont, tenus de faire une déclaration, s'ils entendent.conserver la qualité de Français;- qu'à défaut de cette déclaration dans les délais prescrits, il seront considérés comme Allemands; et qu'au contraire, tous ceux qui ne sont pas nés dans ces territoires n'ont aucune déclaration à faire: et sont Français de plein droit". ARNOULD, L. De l'option des alsaciens-lorrains pour la nationalité française. Paris: Berger-Levrault, 1879. p. 7 ss. Vide, ainda, Ainda sobre o tema: WEISS, André. Manuel de droit international privé. Paris: Sirey, 1914. p. 174 ss., e mais recentemente, WAHL, Alfred. L'option et l'émigration des Alsaciens-Lorrains: 1871-1872. Paris: Ophrys, 1974.
} 
nuar com a nacionalidade original, independentemente de onde ele se encontre, e que "nenhum habitante do territórios cedidos poderá ser processado, assediado, ou procurado na sua pessoa ou em seus bens devido aos seus atos políticos ou militares durante a guerra".

Também o Estado brasileiro se valeu, no século XIX, do instituto da "opção", mas em um contexto completamente diferente daqueles até aqui citados ${ }^{35}$. Nesse sentido, o dispositivo previsto no âmbito do artigo primeiro do decreto n. ${ }^{\circ} 58$-A, de 14 de dezembro de 1889 , emanado pelo governo neorrepublicano realizou a "grande naturalização" com base, justamente, na possibilidade de utilização da "opção" por parte dos imigrantes que aqui se encontravam naquela data:

\begin{abstract}
são considerados cidadãos brasileiros todos os estrangeiros que ja residiam no Brazil no dia 15 de novembro de 1889 , salvo declaração em contrario feita perante a respectiva municipalidade, no prazo de seis mezes da publicação deste decreto ${ }^{36}$.
\end{abstract}

A regra previa a manifestação a respeito da manutenção da nacionalidade de origem, com a consequente perda dela em caso de silêncio por parte do estrangeiro. Do ponto de vista do direito adjetivo, o quarto artigo do decreto regulamentava o procedimento previsto no artigo primeiro. A esse fim, tratava do registro do ato volitivo a ser expressamente manifestado pelo imigrante com o objetivo de manter a cidadania de origem, continuando, desse modo, na condição jurídica de estrangeiro e declinando da concessão feita pelo governo neorrepublicano ${ }^{37}$.

${ }^{35}$ Disponível em: DAL RI JR., Arno. El tratamiento jurídico del extranjero en Brasil: de la "gran naturalización" de la Primera República a la seguridad nacional en el Estado nuevo (1889-1945). In: PALCHETTI, Paolo; MECCARELLI, Massimo (eds.). Derecho en movimiento: personas, derechos y derecho en la dinámica global. Madrid: Dykinson, 2015. p. 113 ss.

${ }^{36} \mathrm{O}$ texto do artigo segundo do mesmo decreto vai em direção similar, quando afirma que: "todos os estrangeiros que tiverem residencia no paiz durante dous annos, desde a data do presente decreto, serão considerados brazileiros, salvo os que se excluirem desse direito mediante a declaração de que trata o art. $1^{\circ}$.

37 "A declaração a que se referem os arts. $1^{\circ}$ e $2^{\circ}$, será tomada perante o secretario da municipalidade ou corporação que provisoriamente a substitua, em livro especialmente destinado a tal fim, e assignada pelo declarante e pelo mesmo secretario ou representante da alludida corporação". O decreto do governo brasileiro não dispunha sobre manifestação de ato volitivo por parte do imigrante com a finalidade de aquisição da nacionalidade brasileira, mas impunha ao mesmo a necessidade de se manifestar expressamente no sentido de continuar a manter o vínculo com a esfera jurídica de origem. Aqueles que não a fizessem no prazo prescrito por lei restava somente a hipótese da nacionalização tácita com a consequente perda também tácita da cidadania original, uma vez que o Estado brasileiro impun-

\subsection{Configurações da "opção" no articulado do Tratado de Saint-Germain-en-Laye}

Os artigos do Tratado de Saint Germain-en-Laye que regem o instituto da "opção" partem da caracterização dos indivíduos que poderão exercê-la. O primeiro requisito encontra-se previsto no artigo $70^{38}$, estar de posse da "pertinenza" (beimetrecht), instituto típico da legislação austríaca de então: os indivíduos que tivessem a "pertinen ₹a" em relação a alguma comuna dos territórios anexados obteriam a nacionalidade do país que passasse a exercer a soberania sobre tal território, em exclusão da cidadania austríaca.

A “opção" propriamente dita surge no texto da lei como exceção à regra do mencionado artigo 70. Contida no artigo 78 do mesmo tratado, previa que:

as pessoas com mais de 18 anos que perderem sua
nacionalidade austríaca e obterem i $\not$ so facto uma nova
nacionalidade segundo o artigo 70 , terão direito no
prazo de um ano a partir da entrada em vigor do
presente Tratado para optar pela nacionalidade do

ha a exclusividade no que concerne a manutenção da nacionalidade brasileira. Sendo até então os maiores fornecedores de imigrantes ao Brasil, os governos da Itália, de Portugal, da Espanha e do Império Austro-Húngaro se manifestaram de modo incisivo contrariamente à "grande naturalização" através de nota coletiva no qual vinha afirmado que o decreto brasileiro era "[...] contraire aux principes généralement acceptés de droit international" e sem fundamento jurídico do momento em que "[...] vise à etablir, en la fondant sur le silence du citoyen étranger, une présomption gratuite, c'est-à-dire la présomption de la volonté de ce dernier de choisir la nationalité brésilienne", se concluía com a afirmação de que “[...] le Potenze firmatarie, protestando contro l'adozione del decreto, auspicavano un riesame della materia" e, no caso em que o Brasil tivesse persistido na sua posição, as mesmas potências teriam considerado o decreto 58-A como "[...] nul et non avenu", conformando a conduta destas aos "[...] principes du droit international et aux intérêts de ses ressortissants". O governo italiano reiterou seus protestos emanando em 1 de outubro do mesmo ano um memorandum enviado às representações diplomáticas do Brasil e dos demais Estados que tinham levantado protestos, afirmando que a “[...] faculté qu'a le Brésil, en tant qu'état souverain de regler les questions ayant trait à la naturalisation des étrangers, n'exclut pas évidemment le droit et le devoir, qu'a le gouvernement italien de provoquer des mesures conformes à l'équité et aux intérêts de sés ressortissants" e que o "[...] le décret brésilien [...] n'offre pás la nationalité brésilienne aux étrangers, il la leur impose, puisque après deux ans il les considere déjà comme ayant acquis la nationalité brésilienne, ou bien les oblige a y renoncer formellement". A respeito, PANZERA, Antonio Filippo. Limiti internazionali in materia di cittadinanza. Napoli: Jovene, 1984. p. 229.

38 "Every person possessing rights of citizenship (pertinenza) in territory which formed part of the territories of the former Austro-Hungarian Monarchy shall obtain ipso facto to the exclusion of Austrian nationality the nationality of the State exercising sovereignty over such territory". 
Estado em que possuía direitos de cidadania antes de adquirir tais direitos no território transferido.

Embora a versão em inglês do tratado utilize, no artigo 70, o conceito de pertinenza/ heimatrecht como traduzível por "cidadania", razões históricas e jurídicas impedem a aproximação dos dois conceitos. Nesse sentido, conforme explica Ester Capuzzo ${ }^{39}$, "pertinenz̧a" ou "beimatrecht", em alemão, se refere à ligação do indivíduo sobretudo com uma comuna específica do território do império $^{40}$. A aquisição se dava por meio do nascimento na comuna em questão, pelo ius sanguinis via paterna, pelo casamento com alguém que tivesse a pertinenza com a comuna, ou, por conta de relações institucionais especiais com a localidade. Por fim, requisito essencial para a aquisição e manutenção da pertinenza era a posse de cidadania austríaca ${ }^{41}$. Muito provavelmente a escolha desse instituto como elemento caracterizador dos indivíduos que passariam a ser nacionais dos Estados que sucediam territorialmente o império, no âmbito do artigo 70, se deu em razão do efetivo vínculo com os territórios que estavam sendo objeto de anexação ${ }^{42}$, algo que a posse da mera cidadania austríaca não poderia certificar. A corroborar essa hipótese encontra-se o texto do artigo 71, que versa, especificamente, sobre as limitações à aquisição da nacionalidade italiana:

mão obstante as disposições do artigo 70, a nacionalidade italiana não deve, no caso de território transferido para a Itália, ser adquirida ipso facto: (1) por pessoas que possuem direitos de cidadania em tal território que não nasceram lá; (2) por pessoas que adquiriram seus direitos de cidadania em tal território após 24 de maio de 1915, ou que o adquiriram apenas em razão de sua posição oficial.

\footnotetext{
39 CAPUZZO, Ester. Dalla pertinenza austriaca alla cittadinanza italiana. Atti della Accademia Roveretana degli Agiati di Scienze Lettere ed Arti, Rovereto, Italia, s. 8, v. 10, n. 2, atti A, 2010. Disponível em: https://agiati.org/atti-a-2010-ii. Acesso em: 05 set. 2020. p. 68.

40 Sobre o assunto: PETRI, Rolf. Cittadinanza, dimora, espulsione. In: OBERMAIR, Hannes; RISSE, Stephanie; ROMEO Carlo (hrsg. von / a cura di). Regionale Zivilgesellschaft in Bewegung: cittadini innanzi tutto. Festschrift für / Scritti in onore di Hans Heiss. Wien: Folio, 2012. p. 37 ss.

${ }^{41}$ Emerge nesse contexto uma significativa colisão entre diferentes culturas jurídicas: enquanto na Itália existia, apenas, o vínculo com o Estado nacional por meio da nacionalidade, no império austríaco, além desse vínculo nacional, subsistia, ainda, um vínculo específico com a cidade (a comuna) por meio da pertinenza, fenômeno que se materializava em direitos e em deveres específicos, além de uma visão de ordenamento mais local do que nacional.

${ }^{42}$ CAPUZZO, Ester. Dalla pertinenza austriaca alla cittadinanza italiana. Atti della Accademia Roveretana degli Agiati di Scienze Lettere ed Arti, Rovereto, Italia, s. 8, v. 10, n. 2, atti A, 2010. Disponível em: https://agiati.org/atti-a-2010-ii. Acesso em: 05 set. 2020. p. 69.
}

Logo após a anexação da Áustria pelo Terceiro Reich, com o Anschluss, a "opção" prevista no Tratado de Saint Germain-en-Laye voltou a ser objeto de debates, com o processo que culminou na emanação da Lei italiana n. ${ }^{\circ} 1.241$, de 21 de agosto de 1939. Fruto do latente descontentamento com a anexação do pós-Primeira Guerra por parte de setores da sociedade germanófona da província de Bolzano ${ }^{43}$ e do novo contexto político envolvendo a Alemanha, a norma previa a possibilidade de indivíduos pertencentes ao grupo étnico-linguístico alemão que tinham adquirido a nacionalidade italiana nos termos do Tratado de Saint Germain, renunciarem a ela para, na sequência, solicitarem a cidadania alemã ${ }^{44}$. Não se tratava, propriamente, de uma inovação legislativa, à medida que o artigo $8^{45}$ da Lei italiana n. ${ }^{\circ}$ 555/1912

43 O descontentamento tirolês com a anexação se acirrou a partir de 1921, quando ocorreu o episódio que ficou conhecido como "Bozner Blutsonntag" (Domingo sangrento de Bolzano), no qual partidários do movimento fascista atacaram participantes de uma tradicional procissão da cidade, sob a cumplicidade das forças de segurança (GROTE, Georg. The South Tyrol question, 1866-2010: from national rage to regional state. Bern: Peter Lang International Academic Publishers, 2012. p. 15-16). Após a ascensão de Mussolini ao poder, Ettore Tolomei, com o aval do regime fascista, colocou em prática em 1923 o programa conhecido como "Provvedimenti pel l'Alto Adige", que pretendia substituir os traços étnicos alemães locais por italianos, inclusive com alterações de nomes e modificações de fachadas e construções (GROTE, Georg. The South Tyrol question, 1866-2010: from national rage to regional state. Bern: Peter Lang International Academic Publishers, 2012. p. 17).

44 A emanação da norma foi negociada entre governo italiano e o III Reich, sendo publicada pouco mais de um ano da anexação da Áustria, agora mera província do Estado alemão. Mesmo tendo descartado a anexação do território de Bolzano à "Grande Alemanha" (FENET, Alain. La question du Tyrol du Sud: un problème de droit international. Paris: Librairie Générale de Droit et de Jurisprudence, 1968. p. 50-51), o acordo buscava alcançar aquela população de etnia alemã disposta a emigrar. O artigo primeiro da lei italiana previa que: "le persone di origine e di lingua tedesca, domiciliate nei comuni dell'Alto Adige, anche se residenti altrove, le quali hanno acquistato la cittadinanza italiana in applicazione del trattato di San Germano, annesso alla legge 26 settembre 1920, n. 1322, e delle norme emanate in esecuzione del trattato stesso, che intendano trasferirsi in Germania ed acquistare la cittadinanza germanica, devono dichiarare di rinunciare alla cittadinanza italiana prima del trasferimento. La presente disposizione si applica, altresì, ai discendenti, cittadini italiani, delle persone indicate nel comma precedente". Sobre o tema: SCROCCARO, Mauro. Dall'Aquila bicipite alla croce uncinata: L'Italia e le opzioni nelle nuove provincie. Trentino, Sudtirolo, Val Canale (1919-1939). Trento: Museo Storico in Trento, 2000.

45 "Perde la cittadinanza: 1. chi spontaneamente acquista una cittadinanza straniera e stabilisce o ha stabilito all'estero la propria residenza; 2. chi, avendo acquistata senza concorso di volontà propria una cittadinanza straniera, dichiari di rinunziare alla cittadinanza italiana e stabilisca o abbia stabilito all'estero la propria residenza. Può il Governo nei casi indicati ai nn. 1 e 2 dispensare dalla condizione del trasferimento dalla residenza all'estero; $[. .$.$] '".$ 
já previa a possibilidade de aquisição de uma cidadania estrangeira, em detrimento da italiana ${ }^{46}$.

\section{0 impacto das normas sobre nacionalidade do Tratado de Saint Germain-en-Laye nos emigrados trentino-tiroleses antes de 1920}

Seguindo aquilo que já em 1877 sugeriram Theóphile Funck-Brentano e Albert Sorel ${ }^{47}$ acerca dos direitos dos cidadãos emigrados, o texto do Tratado de Saint Germain-en-Laye parece trazer normas claras e inequívocas em favor deles. É o que diz, em primeira análise, o artigo 72 da norma internacional:

As pessoas referidas no artigo 71 , bem como aquelas que: (a) anteriormente possuíam direitos de cidadania nos territórios transferidos para a Itália, ou cujo pai, ou mãe, se o pai for desconhecido, possuíam direitos de cidadania nesses territórios [...] podem reivindicar a nacionalidade italiana sujeita às condições previstas no artigo 78 .

Em síntese, aqueles que haviam emigrado dos respectivos territórios antes da anexação — situação de grande parte dos emigrantes trentino-tiroleses que partiram para o Brasil - deveriam se atentar ao que estava previsto no artigo 72, ou seja, a possibilidade de "opção" pela nacionalidade italiana nos termos do artigo 78. É de particular interesse, nesse contexto, o fato de a referência ao artigo 72 flexionar o verbo no passado: em outras palavras, aqueles que tiveram a pertinenza em territórios transferidos para a Itália.

Trata-se de um detalhe importante à medida que os termos do tratado desconheciam o fato de os emigrantes e seus filhos estarem sujeitos à perda automática do vínculo da cidadania austríaca após a emigração, con-

\footnotetext{
46 Após o término da Segunda Guerra, segundo relata Edio Vallini (VALLINI, Edio. La questione dell'Alto Adige. Firenze: Parenti, 1961. p. 153), mais de cem mil alto atesinos tinham renunciado à cidadania italiana para obter a alemã. A Itália, porém, nos termos do Tratado de Paris de 1947 (Anexo IV, item 3, "a"), comprometeu-se a analisar, atentamente, a questão daqueles que, arrependidos, desejassem permanecer em sua terra natal (com a cidadania italiana, portanto). Essas pessoas ficaram conhecidas como os "reoptantes". Em 02 de fevereiro de 1948, seria editado o Decreto n. ${ }^{\circ} 23$, possibilitando a manutenção da cidadania italiana para os alto atesinos que, tendo optado pela cidadania alemã, não obtiveram o certificado de naturalização, ou não fixaram residência na Alemanha.

47 FUNCK-BRENTANO, Théophile; SOREL, Albert. Précis du droit des gens. Paris: E. Plon, 1877. p. 503.
}

forme tinha sido disposto pelo parágrafo segundo do "Decreto relativo à emigração e à ausência ilegítima do estado dos súditos austríacos", emanado em 24 de março de 1832" : "quem quer emigrar deve pedir ao Governo local por meio da Superioridade local e da Capitania do Círculo ou à Delegação a qual pertence o seu domicílio, de ser desvinculado da sua cidadania austríaca do Estado". A perda da condição jurídica vinha reiterada no parágrafo nono da mesma norma: "aqueles que emigram com autorização perdem a qualidade de súditos, e em todas as relações civis e políticas são contemplados como estrangeiros" ${ }^{\prime 4}$.

Após mais de uma década da entrada em vigor do tratado, o jurista italiano Manlio Udina ${ }^{50}$ publicou um artigo em que analisa, com base nos termos dos dispositivos do mencionado tratado, a condição jurídica dos descendentes de emigrados citados no texto do tratado. Em particular, Udina chamava a atenção para a distinção entre os termos utilizados nos artigos 72 e 80 , ou seja, a possibilidade de eleger uma nacionalidade (facoltà di elezione) seria diferente do direito de "opção". Do modo como foi redigida, a norma dispõe, claramente, sobre um direito de "opção" que, uma vez exercido, deve ser respeitado/acatado pelo Estado envolvido. A possibilidade dada aos cidadãos de eleger determinada nacionalidade permanece, ao contrário, como uma faculdade a qual o Estado envolvido não é necessariamente obrigado a acolher.

O texto do artigo 72 , aplicável em relação àqueles que haviam emigrado, poderia, nesse caso, ser enquadrado como uma "eleição". Inclusive, o subsequente artigo $73^{51}$ prevê que o requerimento pode não ser aco-

48 "Patent über die Auswanderung und unbefugte Abwesenheit österreichischer Unterthanen" ou, em italiano, "Patente relativa all'emigrazione ed all'assenza illegittima dallo stato dei sudditi austriaci". Disponível em: ADORNO, Vicenzo (a cura di). Guida alle fonti sull'emigrazione conservate presso l'Archivio Storico del Comune di Trento: fondo ordinamento austriaco (1815-1918). Trento: Provincia Autonoma di Trento, 1998. p. 151-187; e SCHOPF, Franz Joseph. Das gesetzliche Verfahren in Auswanderungsfällen: aus dem allerhöchsten Patente vom 24. März 1832 und den früher erlassenen Verordnungen, wie auch den Paßvorschriften. Wien: Sollinger, 1834.

49 Sobre as possibilidades de impacto da ausência do súdito do território estatal na sua própria condição jurídica, no âmbito dos estados pré-unitários italianos: STORTI, Claudia. Ricerche sulla condizione giuridica dello straniero in Italia dal tardo diritto comune all'età preunitaria. Milano: Giuffrè, 1990. p. 194 ss.

${ }^{50}$ UDINA, Manilo. Sull'acquisto della cittadinanza italiana di pieno diritto in base al Trattato di pace di St. Germain. Rivista di Diritto Internazionale, anno 24, s. 3, v. 11, p. 102-106, 1932. p. 105-106.

51 "The claim to Italian nationality by the persons referred to in 
lhido pela autoridade competente. Ainda, conforme as observações do jurista italiano ${ }^{52}$, a eleição da nacionalidade é indicada com os termos "potranno eleggere", ou "pourront réclamer" (poderão eleger ou solicitar), ao passo que a opção pela nacionalidade (austríaca ou italiana) é indicada como "diritto d'opzione" ou "droit d'option" (direito de opção). Essa distinção entre o direito de "opção" e a faculdade de "eleição" seria fundamental para que as categorias jurídicas envolvidas no Tratado de Saint Germain-en-Laye possam ser compreendidas. ${ }^{53}$

No que se refere à população de língua italiana, presente sobretudo na Província de Trento - o antigo Tirolo italiano - , o maior problema em termos de nacionalidade curiosamente se observaria somente décadas depois, na situação vivida pelos descendentes daqueles que haviam emigrado para outros continentes antes de $1920^{54}$. Nessa época, praticamente sem contato com os consulados da Áustria e da Itália, esses emigrantes não tiveram oportunidade para fazer a opção prevista no Tratado. Tecnicamente passariam a ser considerados apátridas, o que, nos anos vinte do século passado, poderia significar raras possibilidades de tutela jurídica em qualquer lugar que estivessem ${ }^{55}$.

Article 72 may in individual cases be refused bythe competent Italian authority".

52 UDINA, Manilo. Sull'acquisto della cittadinanza italiana di pieno diritto in base al Trattato di pace di St. Germain. Rivista di Diritto Internazionale, anno 24, s. 3, v. 11, p. 102-106, 1932. p. 106.

53 Essa mesma sistemática posteriormente foi utilizada no artigo 19 do Tratado de Paris, de 1947, ao dispor sobre a cidadania para os habitantes de territórios italianos anexados pela Iugoslávia, e no artigo 3 do Tratado de Osimo, ao dispor sobre a restituição de território à Itália por parte da Iugoslávia.

${ }^{54} \mathrm{Na}$ segunda metade do século XIX, mais especificamente a partir do ano de 1875, muitos camponeses trentino-tiroleses emigraram, fugindo de condições socioeconômicas desfavoráveis. Segundo estudos de Renzo Grosselli (GROSSELI, Renzo Maria. Trentamila tirolesi in Brasile: dal racconto di una "tragica epopee" alla scoperta di una emigrazione riuscita. In: GROSSELLI, Renzo Maria (a cura di). Trentamila Tirolesi in Brasile: storia, cultura, cooperazione allo svolupo. Trento: Regione Trentino-Alto Adige, 2005. p. 39), mais de 30.000 trentino-tiroleses emigraram para o Brasil. A colonização trentinotirolesa no Brasil, inaugurada com a expedição Tabacchi para o Espírito Santo (GROSSELLI, Renzo Maria. Vincere o morire: contadini trentini (veneti e lombardi) nelle foreste brasiliane. A cura della Provincia Autonoma di Trento. Trento: Lit. EFFE, 1986. p. 82-83), foi seguida pelo desenvolvimento de colônias em Santa Catarina, Rio Grande do Sul, Paraná e São Paulo. Tais Estados concentram, ainda hoje, grande contingente de descendentes destes imigrantes.

55 Se o desfecho da Primeira Guerra Mundial trouxe maus augúrios para os emigrados, o início da República brasileira, acontecido poucos anos antes garantiu-lhes uma nova condição jurídica - aquela de nacionais brasileiros —, rendendo a eles mais alguns anos de relativa tranquilidade. A naturalização em massa decretada no Rio

\section{A responsabilidade internacional acerca dos cidadãos austríacos trentino-tiroleses emigrados}

Em meio a todo esse complexo contexto em que normas de direito internacional público e de direito internacional privado se entrecruzam, encontra-se a questão da responsabilidade internacional dos dois Estados envolvidos, o italiano e o austríaco, sobre esses indivíduos que emigraram antes de 1920 e seus descendentes.

No que concerne ao Estado austríaco, a possibilidade de responsabilização internacional desaparece perante as normas que constam no decreto imperial de 24 de março de 1832, que determinava a perda da nacionalidade a todo cidadão austríaco que, tendo emigrado, permanecesse no exterior por tempo superior há um ano. Agravando ainda mais a situação, o parágrafo 15 da Lei austríaca de 3 de dezembro de $1863^{56}$, intitulada "sobre a regulamentação das condições da pertinência", determinava que "quem perde a cidadania, terá como consequência a perda de seu direito à pertinência" 57 . O impacto das normas do Tratado de Saint Germain-en-Laye sobre a condição jurídica dos cidadãos austríacos trentino-tiroleses que tinham emigrado há mais de um ano era, portanto, quase inexistente à medida que o próprio ordenamento austríaco, por meio das normas de 1832 e de $1863^{58}$, já tinha determinado a perda da nacionalidade.

de Janeiro, em 14 de dezembro de 1889, cujos dispositivos já foram objeto de análise no âmbito desse artigo, foi, justamente, a norma de direito internacional privado que os poupou da tão temida apatridia. Mas, se não se tornaram apátridas por conta das normativa brasileiras, é certo que, em relação ao ordenamento italiano, não adquiriram qualquer direito. Eram estrangeiros no mais, como quaisquer outros estrangeiros.

${ }^{56}$ Gesetz vom 3. December 1863, "Betreffend die Regelung der Heimatverhältnisse".

57 Com a emanação da Lei Fundamental do Império Austro-Húngaro de 1867 essa situação deveria ter sido alterada, à medida que o seu artigo quarto concedia a liberdade de emigração, salvo em caso de obrigações militares. Todavia, tendo em vista que o respectivo artigo primeiro previa a edição de uma lei específica concernente à cidadania e, considerando que tal lei nunca foi emanada, prevaleceu o entendimento de que a normativa válida relativa à cidadania continuava sendo o decreto imperial de 1832. Disponível em: ADORNO, Vicenzo (a cura di). Guida alle fonti sull'emigrazione conservate presso l'Archivio Storico del Comune di Trento: fondo ordinamento austriaco (1815-1918). Trento: Provincia Autonoma di Trento, 1998. p. 25.

58 A reforma à matéria levada a cabo pela lei austríaca de dezembro de 1896 deixou inalterada a situação da perda da nacionalidade por emigração. 
O Estado italiano, por sua vez, até a emanação da Lei 379/2000, em nenhum momento de sua história, deteve algum tipo de responsabilidade internacional em relação aos cidadãos austríacos trentino-tiroleses que emigraram antes de 1920 e aos seus descendentes. A ausência da "opção" por parte desses indivíduos, portanto, isenta a República Italiana de qualquer responsabilidade internacional. Em outros termos, a partir da conclusão do prazo previsto pelo tratado para a realização da "opção", os imigrantes que deixaram o Tirol Meridional antes de 1920, assim como seus descendentes, continuaram a configurar como estrangeiros ${ }^{59} \mathrm{em}$ relação ao ordenamento italiano, sem qualquer laço jurídico e, portanto, sem que subsista responsabilidade internacional da Itália em relação a eles, salvo no caso em que se encontrassem legalizados permanentemente em outras partes do território italiano como estrangeiros, sendo essa última condição jurídica, a esse ponto, não mais modificável. No caso dos imigrantes e de seus descendentes que se encontravam fora do território italiano e não fizeram a opção, restou, portanto, somente a condição de alienígena em relação ao ordenamento do Reino da Itália, inexistindo a possibilidade de modificar a sua situação jurídica. Para esses descendentes era impossível o reconhecimento da nacionalidade italiana por meio do critério ius sanguinis, conforme previa a Lei n. ${ }^{\circ} 555$, de 1912 , e conforme ainda hoje prevê a Lei n. ${ }^{\circ}$ 91, de 1992. Para eles, a aquisição da nacionalidade italiana passou a se materializar somente com a emanação da Lei n. ${ }^{\circ} 379$, de $2000^{60}$, uma normativa ad hoc e que

\footnotetext{
59 A própria Lei italiana n. ${ }^{\circ}$ 91/92, em seu art. 18, fazendo referência ao art. 9, I, "a", equiparou a situação das pessoas que nasceram no antigo império austro-húngaro, e seus descendentes, a de estrangeiros.

${ }^{60}$ A partir da promulgação em 1992 da Lei italiana n. ${ }^{\circ}$ 91, que versava sobre a aquisição da nacionalidade em particular através do critério "ius sanguinis", mas não contemplava os descendentes de trentino-tiroleses, teve início uma série de movimentos entre as instituições políticas e culturais trentinas em busca de uma via legal que permitisse também a esses a aquisição da nacionalidade italiana. Um primeiro projeto discutido e votado em 1998, que buscava a equiparação da província trentina às demais províncias italianas em termos de nacionalidade - o que possibilitaria aos descendentes serem tutelados pela Lei n. ${ }^{\circ}$ 91/92 — , não foi aceito pelo parlamento. Uma nova proposta foi então apresentada: a emanação de uma norma ad hoc para encaminhar uma solução aos descendentes de trentino-tiroleses. Foi assim que surgiu a Lei n. ${ }^{\circ} 379$, de iniciativa do parlamentar trentino Sandro Schmid. Em 14 de dezembro de 2000, com a promulgação dessa última, a República Italiana, em um ato de direito internacional privado, abriu a possibilidade para que os nascidos nos territórios da monarquia austro-húngara anexados pela Itália e seus descendentes, incluídos os emigrados antes da en-
}

representou verdadeira concessão por parte do Estado italiano, que, em nenhum momento, foi protagonista de responsabilidade internacional acerca dos indivíduos na condição aqui analisada: imigrantes de nacionalidade austríaca nascidos no Tirol Meridional e seus descendentes espalhados pelo mundo.

\section{Considerações finais}

Vários fatos ligados ao processo de anexação dos territórios que pertenceram ao Império Austro-Húngaro por parte da Itália geraram polêmicas consideráveis na sociedade local e na doutrina jurídica de então, em particular no que se refere à ausência de consulta às po-

trada em vigor do Tratado de Saint Germain-en-Laye, adquirissem a nacionalidade italiana. A medida incidia diretamente sobre indivíduos com vínculos de ascendência com o "Tirolo italiano" ou, também, "Welschtirol”. Referida Lei, em que pese ser composta por apenas dois artigos, mostrou-se de uma aplicação bastante complexa, dentre outros fatores, por fazer menção a um território pluriétnico (os territórios que pertenceram à monarquia austro-húngara anexados pela Itália incluíam população de etnia alemã, italiana, reto-romanche, eslovena, croata, dentre outras). Estabeleceu-se uma "Comissão Interministerial" em Roma, no âmbito no Ministério do Interior, composta por membros dos Ministérios da Justiça, das Relações Exteriores e do próprio Ministério do Interior, bem como alguns especialistas no tema oriundos da Universidade Sapienza, de Roma. O objetivo era direcionar a essa comissão os requerimentos feitos com base na referida Lei, para análise e, se cumpridos os requisitos, posterior concessão. Ademais, o Ministério do Interior, em 24 de dezembro de 2001, expediu a Circolare K78, cujo objetivo seria "regulamentar" a Lei n. ${ }^{\circ} 379$, estabelecendo parâmetros para sua aplicação. O sucesso na aprovação da Lei n. ${ }^{\circ} 379$ deve-se sobretudo ao movimento ocorrido entre a instituições como o governo da Província Autônoma de Trento e a Universidade de Trento, a Associação Trentini nel Mondo, o jornal "L'Adige" e várias outras ONGs, patronatos, cooperativas e sindicatos de trabalhadores no exterior que iniciaram a pressão junto aos parlamentares trentinos e ao governo italiano pela emanação de uma norma que garantisse o direito à nacionalidade italiana aos descendentes de trentino-tiroleses emigrados. Sobre a lei e aquisição da nacionalidade italiana por meio do critério "ius sanguinis": BALLARINO, Tito. Cidadania e nacionalidade. In: DAL RI JR., Arno; OLIVEIRA, Odete M. Cidadania e nacionalidade: efeitos e perspectivas nacionais, regionais, globais. 2. ed. Ijuí: Unijuí, 2003. p. 85-93; CLERICI, Roberta. Cidadania plúrima e status pessoal. In: DAL RI JR., Arno; OLIVEIRA, Odete M. Cidadania e nacionalidade: efeitos e perspectivas nacionais, regionais, globais. 2. ed. Ijuí: Unijuí, 2003. p. 95-101.; CLERICI, Roberta. La cittadinanza nell'ordinamento giuridico italiano. Padova: Cedam, 1993.; CLERICI, Roberta. L'acquisto della cittadinanza. In: BONILINI, Giovanni (diretto da). Trattato di diritto di famiglia. Torino: UTET, 2016. v. 1. p. 763-787; CLERICI, Roberta. Commento agli artt. 1, 2, 3, 4, 5, 6, 7, 8, 9, 14, 26 della 1.5 febbraio 1992 n. 91. In:ZACCARIA, Alessio (a cura di). Commentario breve al diritto di famiglia. 4. ed. Padova: Cedam, 2020. p. 2205-2228. 
pulações locais sobre o evento, assim como acerca da condição jurídica atribuída aos indivíduos que as compunham a partir da data de entrada em vigor do tratado.

No que concerne ao primeiro caso, como demonstrado ao longo do artigo, não foi dada voz à população desses territórios por meio da previsão pela norma internacional do instituto do "plebiscito", fenômeno que agravou o já existente descontentamento com a violação das fronteiras culturais e linguísticas, hipótese inicialmente negada pelas potências aliadas e que limitava as ambições da Itália aos territórios habitados por populações de língua italiana. O instituto da "opção" surge no texto pactício, então, como uma solução bastante frágil na tentativa de definir a condição jurídica dos habitantes daqueles territórios, buscando amenizar, concomitantemente, os efeitos colaterais da violação das fronteiras étnicas e linguísticas e da ausência da previsão de "plebiscito". A inserção no texto do instituto da "opção" era, porém, bastante coerente com as lógicas que defendiam a ideia de homogeneidade cultural e linguística próprias dos estados-nação. $\mathrm{O}$ instituto do "plebiscito", ao contrário, tendo sido frequente nos demais casos do processo de unificação italiana, poderia ter fornecido dados sobre o real apoio da população à anexação.

Pode-se inferir, de todo modo, que as percepções quanto a esta ocorrência foram bastante diferentes entre a população de língua italiana e a de língua alemã. Para esses últimos, como visto nos exemplos mencionados, o sentimento em relação ao previsto no tratado foi de violação de princípios internacionais e de aculturação forçada. A grande adesão à lei que incentivava a aquisição da nacionalidade alemã alguns anos depois, em 1939, pode ser tomada como um claro indicativo da baixa aceitação que as disposições pactícias tiveram em meio àquela população.

$\mathrm{Na}$ ciência do direito internacional, ao contrário, as análises acerca do uso da "opção", demonstraram não somente o aceite, mas também salientaram o seu uso frequente em situações análogas. Em termos estritamente jurídicos, os instrumentos utilizados eram válidos, consolidados pela teoria e pela prática, o que assegurou certa estabilidade ao processo de anexação. $\mathrm{O}$ uso da "opção" tutelaria os interesses do estado-nação à medida que os descontentes teriam a possibilidade de emigrar para a Áustria, deixando na Itália somente aqueles "disponíveis" à vinculação jurídica e cultural à nova realidade estatal. As críticas mais significativas emergiam, portanto, no seio da própria população, notadamente aquela de língua alemã, o que acarretou conflitos nas décadas de 1960/70 61 e, até o presente, fortes questionamentos, atenuados pela concessão de autonomia administrativa e financeira por parte da Itália, sob a tutela da Áustria.

O segundo ponto objeto de análise trata do impacto das normas do Tratado de Saint Germain-en-Layé sobre, justamente, a condição jurídica dos habitantes de tais territórios, regulada através do instituto da "opção", como previsto nos artigos 70 a 78, com efeitos sobretudo no que concerne aos descendentes de indivíduos emigrados antes de 1920. O artigo 72, nessa perspectiva, aplicável aos que haviam emigrado, classificando o exercício do instituto como uma mera "possibilidade", que poderia ou não ser acatada pela autoridade competente. Não era, portanto, efetivamente um direito. A questão é relevante à medida que ao longo dos anos surgiram inúmeros questionamentos quanto à responsabilidade internacional por parte da Itália, assim como da Áustria, em relação a esses emigrados que, na grande maioria das vezes se encontravam em locais distantes ou até mesmo inacessíveis, muitos no interior do continente americano, sem acesso às representações consulares, não tendo com isso efetivo acesso à "opção" prevista no tratado ${ }^{62}$.

${ }^{61}$ Sobre o assunto: ITALIA. Relazioni sullinchiesta condotta su episodi di terrorismo in Alto Adige presentate rispettivamente dai senatori Boato e Bertoldi. X Legislatura. Doc. 23, n. 52. Roma: Senato della Repubblica; Camera dei Deputati, 1992. Disponível em: https://www.senato.it/service/PDF/PDFServer/BGT/909972.pdf. Acesso em: 06 nov. 2020.; ainda sobre o assunto: GROTE, Georg. The South Tyrol question, 1866-2010: from national rage to regional state. Bern: Peter Lang International Academic Publishers, 2012. p. 99 ss.

${ }^{62}$ Como já mencionado, os maiores questionamentos surgiram a partir de 1992, ano em que foi promulgada a lei de cidadania italiana n. ${ }^{\circ}$ 91, que não incluiu os descendentes de imigrantes trentino-tiroleses em seus vantajosos termos (PISONI, Ferruccio. Un solco lungo 50 anni: l'Associazione Trentini nel Mondo dal 1957 al 2007. Trento: Grafiche Dalpiaz, 2007. p. 141). As associações de representação das comunidades trentinas existentes em vários países passaram a argumentar que tais imigrantes não realizaram a "opção", perdendo $\mathrm{o}$ direito à cidadania italiana, por razões que eram alheias à sua vontade. O parlamentar ítalo-trentino Sandro Schmid resumiu a questão da seguinte forma ao justificar o projeto de lei A.C. 4541/98, que pretendia equiparar os descendentes de imigrantes trentinos aos descendentes de imigrantes das demais províncias italianas: "Si tratta di una questione antica di forte contenuto umano, prima ancora che sociale e politico. Una discriminazione ingiusta verso $i$ trentini-altoatesini costretti in quell'epoca all'emigrazione, discriminazione mai sanata [...] È noto come a seguito delle correnti migratorie italiane [...] si sono create comunità assai dinamiche che a tutt'oggi si dichiarano di origine italiana, conservano costumi e tradizioni italiani e usano correttamente la vecchia lingua dialettale. Tali correnti provenivano anche da territori allora sotto la sovranità austro-ungarica per 
Os parágrafos $4^{\circ}, 9^{\circ}$ e $10^{\circ}$ do Decreto imperial austríaco de 1832, que preveem a perda da nacionalidade para os emigrantes, eliminam de imediato a possibilidade de responsabilização da Áustria. Tais indivíduos, consequentemente, estavam excluídos das relações envolvendo Itália e Áustria nos termos do tratado. Para eles, restou uma concessão residual lhes permitindo optar pela cidadania italiana dentro do prazo de um ano a partir da vigência do Tratado.

A imputação de responsabilidade internacional à Itália no que concerne àqueles que não realizaram a "opção", por sua vez, também deve ser eliminada. As obrigações fixadas para o estado italiano na Conferência de Saint Germain-en-Layé se referiam, exclusivamente, aos cidadãos austríacos que residiam nos territórios por ela anexados. Aqueles que haviam emigrado, já tendo os laços cortados em relação à Áustria devido à perda da nacionalidade disposta pela norma de 1832, nenhum direito poderiam exigir em relação à Itália. A única possibilidade que lhes restava, mais uma vez, era tão somente utilizarem-se da "opção" dentro do prazo previsto, nos termos do artigo 72. Consequentemente, cumprido o prazo de um ano para se realizar a "opção", não haveria como estabelecer qualquer vínculo entre a Itália e os emigrados dos territórios anexados que não optaram pela cidadania italiana.

Aqueles que haviam emigrado antes de 1920, data da eficácia internacional do tratado, portanto, já não possuíam vínculo com a Áustria, pois a perda da cidadania austríaca era consequência da emigração, assim como não possuíam qualquer vínculo com a Itália. Os descendentes desses indivíduos não receberiam a transmissão de direito à nacionalidade austríaca ou italiana através do critério do "ius sanguinis", devendo esperar a realização de uma concessão graciosa do Estado italiano, consubstanciada na normativa ad hoc Lei n. ${ }^{\circ}$ 379/2000, que permitiu aos originários dos antigos territórios do império austro-húngaro anexados pela Itália, e seus des-

cui la cittadinanæa italiana, riconosciuta jure sanguinis agli oriundi italiani, non viene riconosciuta a coloro che erano emigrati prima del trattato di Saint Germain (10 settembre 1919), salvo specifica opzione da esercitare entro un anno dall'entrata in vigore del trattato. Purtroppo tale opzione non è stata formulata. Le associazioni degli emigrati, in base alla loro attiva presenza fra queste comunità, ritengono che la mancata opzione sai dovuta in primo luogo all'assenza di informazione in merito ed alle grandi difficoltà se non alla vera e propria impossibilità materiale di accedere alle autorità consolar" (ITALIA. Proposta di legge d'iniziativa del deputato Schmid. n. 4541. Atti parlamentari. Camara dei Deputati. XIII Legislatura. Roma: Camara dei Deputati, 1998. Disponível em: http://leg13.camera.it/_dati/leg13/lavori/ stampati/pdf/4541.pdf. Acesso em: 06 nov. 2020.). cendentes, a aquisição da cidadania italiana. Até então, a condição jurídica dos filhos, netos, bisnetos e trinetos de emigrados trentinos-tiroleses antes de 1920 era de "estrangeiro" perante o ordenamento italiano, com todas as consequências advindas de tal situação.

\section{Referências}

ADORNO, Vicenzo (a cura di). Guida alle fonti sull'emigrazione conservate presso l'Archivio Storico del Comune di Trento: fondo ordinamento austriaco (1815-1918). Trento: Provincia Autonoma di Trento, 1998.

ARNOULD, L. De l'option des alsaciens-lorrains pour la nationalité française. Paris: Berger-Levrault, 1879.

BALLARINO, Tito. Cidadania e nacionalidade. In: DAL RI JR., Arno; OLIVEIRA, Odete M. Cidadania e nacionalidade: efeitos e perspectivas nacionais, regionais, globais. 2. ed. Ijuí: Unijuí, 2003.

BISOCCHI, Carlo. Acquisto e perdita della nazionalità nella legislazione comparata e nel diritto internazionale. Milano: Hoepli, 1907.

BOLLER, Daiana. Welschtirol: il territorio trentino nell'impero asburgico. Bolzano: Athesia, 2014.

BONFILS, Henri. Manuel de droit international public. Paris: A. Rousseau, 1905.

CAPUZZO, Ester. Dalla pertinenza austriaca alla cittadinanza italiana. Atti della Accademia Roveretana degli Agiati di Scienze Lettere ed Arti, Rovereto, Italia, s. 8, v. 10, n. 2, atti A, 2010. Disponível em: https://agiati.org/atti-a2010-ii. Acesso em: 05 set. 2020.

CLERICI, Roberta. Cidadania plúrima e status pessoal. In: DAL RI JR., Arno; OLIVEIRA, Odete M. Cidadania e nacionalidade: efeitos e perspectivas nacionais, regionais, globais. 2. ed. Ijuí: Unijuí, 2003. p. 95-101.

CLERICI, Roberta. Commento agli artt. 1, 2, 3, 4, 5, 6, 7, 8, 9, 14, 26 della 1. 5 febbraio 1992 n. 91. In: ZACCARIA, Alessio (a cura di). Commentario breve al diritto di famiglia. 4. ed. Padova: Cedam, 2020.

CLERICI, Roberta. L'acquisto della cittadinanza. In: BONILINI, Giovanni (diretto da). Trattato di diritto di famiglia. Torino: UTET, 2016. v. 1.

CLERICI, Roberta. La cittadinanza nell'ordinamento giuridico italiano. Padova: Cedam, 1993. 
CORSINI, Umberto. Problemi politico-amministrativi del Trentino nel nesso provinciale tirolese, 1815-1918. In: VALSECCHI, Franco; WANDRUSZKA, Adam (a cura di). Austria e province italiane 1815-1918: potere centrale e amministrazioni locali. Bologna: Il Mulino, 1977.

COVA, Paolo. Der große Betrug: das optiondrama der deustchsrachigen Inseln im Trentino. Palai en Bersntol: Istituto Culturale Mocheno, 2014.

D’AZEGLIO, Luigi Taparelli. Della naz̧ionalità. Genova: Ponthenier, 1847.

DAL RI JR., Arno. A nação contra o Estado: a ciência do direito internacional no "Risorgimento" italiano. Anuário Brasileiro de Direito Internacional, v. 6, p. 6, 2011.

DAL RI JR., Arno. El tratamiento jurídico del extranjero en Brasil: de la "gran naturalización" de la Primera República a la seguridad nacional en el Estado nuevo (1889-1945). In: PALCHETTI, Paolo; MECCARELLI, Massimo (eds.). Derecho en movimiento: personas, derechos y derecho en la dinámica global. Madrid: Dykinson, 2015.

DAL RI JR., Arno. Mancini in the Platine Basin: the reception of the Principle of Nationalities in Argentina, Uruguay and Brazil. Forum Historiae Iuris. Internetzeitschrift für Rechtsgeschichte in Europa. 2018. Disponível em: https://forhistiur.de/en/2018-12-dalri-jr/abstract/?l=en. Acesso em: 06 nov. 2020.

DURANDO, Giacomo. Della nazionalità italiana: saggio politico-militare. Losanna: Bonamici, 1846.

FENET, Alain. La question du Tyrol du Sud: un problème de droit international. Paris: Librairie Générale de Droit et de Jurisprudence, 1968.

FERRANDI, Maurizio. Ettore Tolomei: l'uomo che inventò l'Alto Adige. Trento: Publilux, 1986.

FUNCK-BRENTANO, Théophile; SOREL, Albert. Précis du droit des gens. Paris: E. Plon, 1877.

GROSSELI, Renzo Maria. Trentamila tirolesi in Brasile: dal racconto di una "tragica epopee" alla scoperta di una emigrazione riuscita. In: GROSSELLI, Renzo Maria (a cura di). Trentamila Tirolesi in Brasile: storia, cultura, cooperazione allo svolupo. Trento: Regione TrentinoAlto Adige, 2005.

GROSSELLI, Renzo Maria. Vincere o morire: contadini trentini (veneti e lombardi) nelle foreste brasiliane. A cura della Provincia Autonoma di Trento. Trento: Lit. EFFE, 1986.

GROTE, Georg. The South Tyrol question, 1866-2010: from national rage to regional state. Bern: Peter Lang International Academic Publishers, 2012.

GRUBER, Alfons. Storia del sudtirolo: eventi cruciali del XX secolo. Bolzano: Athesia, 2010.

HAAS, Hanns. Österreich und die Alliierten 19181919. In: ACKERL, Isabella (hrsg.). Saint-Germain 1919: Protokoll des Symposiums am 29. und 30. Mai 1979 in Wien. Wien: Geschichte und Politik, 1989.

HANISCH, Ernst. Der große Illusionist: Otto Bauer (1881-1938). Wien: Böhlau, 2011.

ITALIA. Atti Parlamentari. Camera dei Deputati. XXIV Legislatura. 1. sessione. Roma: Camera dei Deputati, 1919.

ITALIA. Proposta di legge d'iniziativa del deputato Schmid. n. 4541. Atti parlamentari. Camara dei Deputati. XIII Legislatura. Roma: Camara dei Deputati, 1998. Disponível em: http://leg13.camera.it/_dati/leg13/lavori/stampati/pdf/4541.pdf. Acesso em: 06 nov. 2020.

ITALIA. Relazioni sull'inchiesta condotta su episodi di terrorismo in Alto Adige presentate rispettivamente dai senatori Boato e Bertoldi. X Legislatura. Doc. 23, n. 52. Roma: Senato della Repubblica; Camera dei Deputati, 1992. Disponível em: https://www.senato.it/service/PDF/PDFServer/ BGT/909972.pdf. Acesso em: 06 nov. 2020.

KNIPPENBERG, Hans; MARKUSSE, Jan. Nationalising and Denationalising European Border Regions, $1800_{-}$ 2000: views from Geography and History. Berlin: Springer Science, 2012.

KRAMER, Johannes. La toponomastica altoatesina nel contesto europeo. Archivio per l'Alto Adige, 2003. v. 4.

LE REIVINDICAZIONI italiane illustrate alla Conferenza di Parigi: il memoriale dell'On. Barzilai. Il Messaggero, Roma, 12 mar. 1919.

MANCINI, Pasquale S. Direito internacional. Ijuí: Unijuí, 2003.

MAZZINI, Giuseppe. Nazionalità: qualche idea su una costituzione nazionale. In: Edizione nazionale degli scritti di Giuseppe Mazzini. Imola: Galeati, 1908. v. 6.

NYS, Ernest. Le droit international: les principes, les théories, les faits. Bruxelles: Moens, 1912. t. 2. 
ÖSTERREICH. Die Trauerfeier in Innsbruck: Heimatliches. Bozner Nachrichten, Bolzano, n. 233, ano 28, p. 1-2, 12 out. 1920. Disponível em: https://digital.tessmann.it/tessmannDigital/Zeitungsarchiv/Seite/Zeitung/37/1/13.10.1920/130371/1. Acesso em: 06 nov. 2020 .

PAGANO, Vincenzo. Del diritto della nazionalità italiana. Napoli: Rondinella, 1861.

PANZERA, Antonio Filippo. Limiti internazionali in materia di cittadinanza. Napoli: Jovene, 1984.

PETRI, Rolf. Cittadinanza, dimora, espulsione. In: OBERMAIR, Hannes; RISSE, Stephanie; ROMEO Carlo (hrsg. von / a cura di). Regionale Zivilgesellschaft in Bewegung: cittadini innanzi tutto. Festschrift für / Scritti in onore di Hans Heiss. Wien: Folio, 2012.

PISONI, Ferruccio. Un solco lungo 50 anni: l'Associazione Trentini nel Mondo dal 1957 al 2007. Trento: Grafiche Dalpiaz, 2007.

RENZI, William A. In the shadow of the sword: Italy's neutrality and entrance into the Great War, 1914-1915. New York: Peter Lang, 1987.

REUT-NICOLUSSI, Eduard. Tyrol under the axe of Italian fascism. London: Allen \& Unwin Limited, 1930.

ROMAGNOSI, Gian Domenico. La scienza delle costituzioni. Firenze: A Spese Degli Editori, 1850.

SCHOBER, Richard. Il Trentino durante il periodo di unione al Tirolo: 1815-1918. In: VALSECCHI, Franco; WANDRUSZKA, Adam (org.). Austria e province italiane 1815-1918: potere centrale e amministrazioni locali. Bologna: Il Mulino, 1977.

SCHOPF, Franz Joseph. Das gesetzliche Verfahren in Auswanderungsfällen: aus dem allerhöchsten Patente vom 24. März 1832 und den früher erlassenen Verordnungen, wie auch den Paßvorschriften. Wien: Sollinger, 1834.

SCHÜSSEL, Wolfgang. Federalism in a changing world, learning from each other: scientific background, proceedings, and plenaries of the International Conference on Federalism 2002. In: BLINDENBACHER, Raoul; KOLLER, Arnold (org.). International Conference on Federalism. University of St. Gallen, 2002. Montreal: McGillQueen's University Press, 2003. p. 567-570.

SCROCCARO, Mauro. Dall'Aquila bicipite alla croce uncinata: L'Italia e le opzioni nelle nuove provincie. Tren- tino, Sudtirolo, Val Canale (1919-1939). Trento: Museo Storico in Trento, 2000.

SINHA, Thomas. Il sindaco di Bolzano scrive al sindaco di Trento: Historegio. Ufficio comune dell'EUREGIO Tirolo - Alto Adige - Trentino. Disponível em: https:/ / historegio.europaregion.info/it/settimanaattuale-100-anni-fa.asp?news_action $=4 \&$ news_article_ $\mathrm{id}=644028$ \#accept-cookies. Acesso em: 15 out. 2020.

STOERK, Félix. Option und Plebiscit bei Eroberungen tend Gebietscessionen. Leipzig: Duncker und Humblot, 1879.

STORTI, Claudia. Pasquale Stanislao Mancini. In: BIROCHI, Italo; CORTESE, Ennio; MATTONE, Antonello; MILETTI, Marco Nicola (a cura di). Dizionario Biografico dei Giuristi Italiani: XII - XX secolo. Bologna: Il Mulino, 2013. v. 2.

STORTI, Claudia. Ricerche sulla condizione giuridica dello straniero in Italia dal tardo diritto comune all'età preunitaria. Milano: Giuffrè, 1990.

TRATADO de Frankfurt = Traité de Francfort. Alemanha, 10 maio 1871. Disponível em: https://mjp. univ-perp.fr/traites/1871 francfort.htm. Acesso em: 20 set. 2020.

TRATADO de Londres = Treaty of London. Reino Unido, 26 abr. 1915. In: GREAT BRITAIN. Parliamentary Papers. London: LI Cmd. 671, Miscellaneous, n. 7, p. 2-7, 1920.

TRATADO de Osimo = Trattato di Osimo. Itália: 10 nov. 1975. Disponível em: https://www.unimc.it/ maremap/it/data-jus/files-accordi-bilaterali-conclusida-italia/accordi-con-la-rsfy-stati-successori-sloveniacroazia-rfy-montenegro/1975Osimo'Treaty.pdf/view. Acesso em: 20 set. 2020.

TRATADO de Paris = Traité de Paris. França: 10 fev. 1947. Disponível em: https://basedoc.diplomatie. gouv.fr/exl-php/util/documents/accede_document. php?1603132224463. Acesso em: 20 set. 2020.

TRATADO de Saint-Germain-en-Laye = TraitédeSaintGermain-en-Laye. França: 10 set. 1919. Disponível em: https:/ / mjp.univ-perp.fr/traites/1919saintgermain. htm\#pr. Acesso em: 20 set. 2020.

TRATADO de Turim = Traité de Turin. Itália: 24 mar. 1860. Disponível em: https://mjp.univ-perp.fr/ traites/1860turin.htm. Acesso em: 20 set. 2020. 
UDINA, Manilo. Sull'acquisto della cittadinanza italiana di pieno diritto in base al Trattato di pace di St. Germain. Rivista di Diritto Internazionale, anno 24, s. 3, v. 11, p. 102-106, 1932.

VALLINI, Edio. La questione dell'Alto Adige. Firenze: Parenti, 1961.

VIDARI, Gian Savino Pene. La prolusione di Pasquale Stanislao Mancini sul principio di nazionalità (1851). In: CAZZETTA, Giovanni (a cura di). Retoriche dei giuristi e costruzione dellidentità nażionale. Bologna: Il Mulino, 2013.

WAHL, Alfred. L'option et l'émigration des Alsaciens-Lorrains: 1871-1872. Paris: Ophrys, 1974.

WEISS, André. Manuel de droit international privé. Paris: Sirey, 1914.

ZIEGER, Antonio. Storia della Regione Trentina. 2. ed. Trento: Dolomia, 1981. 
Para publicar na Revista de Direito Internacional, acesse o endereço eletrônico www.rdi.uniceub.br ou www.brazilianjournal.org.

Observe as normas de publicação, para facilitar e agilizar o trabalho de edição. 